\title{
Treating empyema thoracis using video-assisted thoracoscopic surgery and open decortication procedures: a systematic review and meta-analysis by meta-mums tool
}

\author{
Massoud Sokouti ${ }^{1}$, Ramin Sadeghi ${ }^{1}$, Saeid Pashazadeh², Saeed Eslami Hasan Abadi ${ }^{3}$, \\ Mohsen Sokouti ${ }^{4}$, Morteza Ghojazadeh ${ }^{5}$, Babak Sokouti ${ }^{6}$
}

\author{
${ }^{1}$ Nuclear Medicine Research Center, Mashhad University of Medical Sciences, \\ Mashhad, Iran \\ ${ }^{2}$ Department of Computer and Electrical Engineering, University of Tabriz, Tabriz, Iran \\ ${ }^{3}$ Department of Medical Informatics, Faculty of Medicine, Mashhad University \\ of Medical Sciences, Mashhad, Iran \\ ${ }^{4}$ Department of Cardiothoracic Surgery, Tabriz University of Medical Sciences, Tabriz, \\ Iran \\ ${ }^{5}$ Research Center for Evidence-Based Medicine, Tabriz University of Medical Sciences, \\ Tabriz, Iran \\ ${ }^{6}$ Biotechnology Research Center, Tabriz University of Medical Sciences, Tabriz, Iran
}

Submitted: 7 June 2018

Accepted: 11 July 2018

Arch Med Sci 2019; 15 (4): 912-935

DOI: https://doi.org/10.5114/aoms.2018.77723

Copyright (c) 2018 Termedia \& Banach

\section{Abstract}

Introduction: Introduction: The optimal treatment of empyema thoracis is still debatable between academics and surgeons. This study reviews advantages and disadvantages of video-assisted thoracoscopic surgery (VATS) and open thoracotomy decortication (OTD) considering outcomes of empyema thoracis.

Materials and methods: A descriptive Boolean query was used for searching three databases to extract the published studies up to 27 March 2017. The outcomes of VATS and OTD were extracted and assessed by random-effects model of meta-analysis. The Egger's test and trim-and-fill method were used for analyzing publication bias, and, meta-regression and subgroup analyses were done for determining heterogeneity.

Results: A total of 2219 patients, from 13 studies, meeting the inclusion criteria were selected and subjected to further analyses. Of 2219 patients, 1120 were treated by VATS and the remaining were subjected to OTD. During VATS, 252 patients were converted to OTD. Forest plots showed that VATS was far superior in terms of incidence of duration of hospital stay and operative time (SMDs $=1.189,1.565 ; p<0.001,<0.001)$ compared to OTD. Mortality, prolonged air leakage, wound infection, and recurrence rates (ORs $=1.234,2.564,1.363,1.962 ; p=0.576,0.077,0.0692,0.4)$ had no advantages for both procedures while failure or conversion rate $(\mathrm{OR}=0.198$, $p<0.001)$ of VATS was more than those of OTD.

Conclusions: The results of the current research suggest no trends of superior outcomes with VATS in the treatment of empyema thoracis. Hence, VATS and OTD could be recommended as treatments for empyema thoracis.

Key words: empyema thoracis, video-assisted thoracoscopic surgery, open thoracotomy, decortication, systematic review, meta-analysis, trim and fill.

\author{
Corresponding authors: \\ Babak Sokouti PhD \\ Biotechnology \\ Research Center \\ Tabriz University \\ of Medical Sciences \\ Tabriz, Iran \\ Phone: +98 4133364038 \\ E-mail: b.sokouti@gmail.com \\ Ramin Sadeghi MD \\ Nuclear Medicine \\ Research Center \\ Mashhad University \\ of Medical Sciences \\ Mashhad, Iran \\ E-mail: raminsadeghi1355@ \\ yahoo.com
}




\section{Introduction}

Empyema thoracis is a disease originally diagnosed and treated by Hippocrates about 2,400 years ago. Through this disease, the pleural cavity is filled with pus, which is commonly caused by pneumonia $[1,2]$. The mortality rate in this disease is as high as 15\% [2]. Nowadays, reports show that about one million patients in the United States of America are hospitalized due to pneumonia, with $40 \%$ and $15 \%$ of them suffering from progressed pleural effusion and developed empyema thoracis, respectively [3].

The American Thoracic Society (ATS) has divided the evolution of pleural empyema into three stages. Stage I is the exudative phase. In stage II, mostly known as the fibrinopurulent phase, the effusion is converted to pus. However, thoracoscopy, video-assisted thoracoscopic surgery (VATS), and rarely open decortication are recommended to patients with loculations or peel. Finally, in stage III, pleura thickening with trapped lung may occur.

The existing surgical procedures for treating empyema thoracis in stages II and III can be either VATS or open decortication [4]. In 1918, the open decortication was performed by Graham and Bell for the first time and introduced for precise removal of the fibrous layer to allow lung re-expansion [2]. Also, VATS was standardized by Machinlay and Landrenea in 1988 [5, 6]. To treat empyema, both VATS and open decortication could be regarded as aggressive surgical approaches [4]. The mortality and morbidity rates after decortication were reported to be still close to 10\% [2].

Today, the number of published articles in wellknown journals is dramatically increasing and effectively defining the role of VATS in the treatment of empyema thoracis. However, the outcomes of both VATS and open decortication remain ambiguous.

Moreover, there is no randomized controlled trial (RCT) study in the literature [7-9]. In this regard, a common recognized approach to identify the advantages and disadvantages of two treatment procedures is to perform a meta-analysis to analyze the information extracted from the systematic reviews.

The subjects of the current systematic review and meta-analysis were selected based on Patients, Intervention, Comparison, and Outcomes (PICO) statements. The patients are those infected by empyema thoracis. The intervention includes two treatment procedures: (1) open thoracotomy decortication and (2) VATS decortication; finally, the patients' answers to components defined in this study (i.e., postoperative prolonged air leakage, mortality, recurrence, failure or converted to thoracotomy, operating time, hospital stay, wound infection) are compared. However, academic researchers and surgeons still debate what the rec- ommended treatment for effective management of empyema thoracis is [10].

\section{Material and methods}

\section{Search strategy}

A systematic search was carried out on Google Scholar, PubMed, and Scopus electronic databases from inception until March 27, 2017, in accordance with Preferred Reporting Items for Systematic Reviews and Meta-Analyses (PRISMA) statement $[11,12]$. To extract the relevant published papers a descriptive Boolean query was used: Query: Decortication AND Empyema AND (VATS OR video-assisted thoracoscopy surgery) AND ((open thoracotomy) OR (open surgery)).

For possible inclusion/exclusion of the articles in/from the study, the databases were searched using the "All Fields" option. Two anonymous investigators explored the extracted articles based on title, abstract, and full content where necessary.

\section{Inclusion and exclusion criteria}

All retrospective and cohort prospective studies in English including open thoracotomy surgery and VATS decortication surgery were considered for inclusion in this study.

All types of articles (i.e., full, original, review, abstract, epidemiologic studies, and meta-analysis) with unclear and inadequate data were excluded. All non-English published studies, except one abstract that had useful information, were excluded. The required data from the final eligible included studies were extracted into an Excel spreadsheet for further analyses.

The pooled analysis was performed using the odds ratio and standard mean difference (SMD) calculated for the studies of interest.

\section{Meta-analysis process}

The CMA version 2.2.064 [13] and Meta-MUMS tool were used. The Meta-MUMS tool, developed in MATLAB R2013a, provides an environment for carrying out the current meta-analysis with limited features including fixed-effects, random-effects meta-analyses, heterogeneity test, and publication bias. These analyses were done by calculating the odds ratio, log-odds ratio, and standard mean differences that are then presented as forest plots with high resolution. Heterogeneity was assessed by calculating Cochran's $Q$ and $R^{2}[14]$. Moreover, Egger's test [15] was performed along with illustrative funnel plots in both fixed-effect and random-effect meta-analyses. Additionally, this tool was used to perform the meta-analysis within two groups using the term "data type" as dichotomous; i.e., it included events, mean, standard de- 
viation, and sample size of each group [14]. These data were imported and exported as Excel files and illustrated as any type of image files.

\section{Patients' characteristics}

The patients had thoracic empyema with positive clinical signs, confirmed by imaging techniques such as chest radiography, thoracic computed tomography (CT) scans, and ultrasonography. Adult patients with complicated parapneumonia and post-pneumonia in advanced stages II or III were considered for this purpose.

\section{Surgery techniques}

\section{Video-assisted thoracoscopy decortication}

This procedure could be performed for the patients for whom the chest tube drainage was a failure or when the lung did not re-expand after thoracentesis or tube thoracostomy. In the patients with thick pus or the presence of pleural thickening on the CT scan, and loculated fluid and debris, VATS was the recommended treatment procedure. After breaking down the loculations and lavaging the pleural space extensively, chest tubes should be placed carefully. In complicated types of stage II and special situations of stage III, the empyema thoracis was also treated by VATS. Any VATS failures, which mostly could happen at the late stages of empyema, were converted to open thoracotomy decortication.

\section{Open thoracotomy decortication}

Open thoracotomy decortication could be performed in almost all complicated types of stages II, III, radical, and VATS failure in treating empyema thoracis. This technique has been applied for the removal of fibrous tissue and peel exclusively from the parietal and visceral pleura to improve the lung re-expansion. Decortication relies on lung elasticity to fill the cavity and significantly improve the vital capacity, and lung perfusion and ventilation.

\section{Outcome measures}

Clinical outcomes were assessed by the disappearance of pleural fluid and full expansion of the affected lung. The postoperative prolonged air leakage, mortality, recurrence, failure (i.e., unsuccessful treatment of either open thoracotomy or VATS decortications) or converted procedures, postoperative hospital stay, times of operations, and wound infection were considered as clinical outcomes for both treatment procedures.

The reported postoperative complications include postoperative prolonged air leakage, wound infection, pleural space operation, blood trans- fusion, deep vein thrombosis, chylothorax, diaphragmatic lesion, atrial fibrillation, pneumonia, seroma, subcutaneous emphysema, intensive care unit (ICU) stay, thoracostomy drainage, morbidity, pain, paresthesia, bleeding after operation, myocardial infarction, cholecystitis, atelectasis, acute respiratory distress syndrome (ARDS), reintubation, tracheostomy, other pulmonary complication, ventricular arrhythmia, other hematologic complication, urinary tract infection, acute renal failure, other medical complication, other surgical complication, readmission, postoperative complication, atrial arrhythmia, bronchopneumonia, and ventilator dependence/support.

The reasons for conversion were technical inability, incomplete decortication, massive bleeding during operation, and life-threatening trauma to the adjacent organs such as great vessels.

\section{Statistical analysis}

For pooling the results from the studies of interest, a random-effects model was used. To illustrate the pooled results graphically, forest plots were used. Two heterogeneity indices - the Cochran $Q$ test with a $p<0.05$ and the $R^{2}$ index (percentage of variation across studies) - were used [14]. After generating the funnel plots and performing the required regression modeling such as intercept of Egger's regression, and the $p$-values, the publication bias was assessed [15]. Based on various studies for assessing the publication bias, $p$-values less than 0.05 were regarded as significant [15-18]. The statistical analysis of all data was performed using both Meta-MUMS and CMA version 2.2.0.064 [13]. However, as the same results were obtained in terms of values and patterns of illustrations, only those for the MetaMUMS tool (i.e., the implemented tool) will be demonstrated and discussed.

In the presence of heterogeneity, mixed-effects meta-regression for sample size difference, published year, hospital stay difference, latitude, and longitude was performed.

To explain the variance between studies, subgroup analysis was performed based on sample size (ideal = subgroup A and non-ideal = subgroup B) (a sample size is regarded as ideal if the sample size is more than 30 and the sample size difference is less than 63; otherwise the sample size is non-ideal), continent (America, Asia, Europe), and published year (Before 2010 = subgroup A and after 2010 = subgroup B).

The trim and fill method is a nonparametric and simple funnel plot-based tool used in metaanalysis for determining and adjusting the publication bias. In this methodology (also implemented in Meta-MUMS), the number of missing or unpublished studies that needs to be present in the 
meta-analysis is predicted along with their effects on the outcome $[19,20]$.

\section{Results}

\section{Characteristics of studies}

In this work, 2835 potentially relevant studies were identified and retrieved from the initial search of databases including Google Scholar, Scopus, and PubMed (Figure 1). After removing duplicates and applying the inclusion and exclusion criteria, only 13 articles remained. These studies included a total of 2219 patients treated with VATS and open thoracotomy decortication. Out of these, 1624 patients were treated with VATS, and 252 of these were failures and were converted. Additionally, 1099 patients were treated with open thoracotomy decortication (252 patients were converted and included).

Of 13 studies, 3 took place in the United Kingdom, 2 in the United States of America, 1 in China, 1 in Taiwan, 1 in Saudi Arabia, 1 in South Korea, 1 in Turkey, 1 in Italy, 1 in Brazil, and 1 in Switzerland.

One study [1] was prospective and the remaining ones were retrospective studies in nature [4, 21-31]. Tables I and II summarize the characteristics, demographics, type of procedures, outcomes, hospital stays, and times of operations for two surgical treatment procedures. Moreover, as all of the postoperative complications cannot be considered as one group, they have been considered as separate groups as postoperative prolonged air leakage, wound infection, pleural space operation, blood transfusion, deep vein thrombosis, chylothorax, diaphragmatic lesion, atrial fibrillation, pneumonia, seroma, subcutaneous emphysema, ICU stay, thoracostomy drainage, morbidity, pain, paresthesia, bleeding after operation, myocardial infarction, cholecystitis, atelectasis, ARDS, reintubation, tracheostomy, other pulmonary complication, ventricular arrhythmia, other hematologic complication, urinary tract infection, acute renal failure, other medical complication, other surgical complication, readmission, postoperative complication, atrial arrhythmia, bronchopneumonia, and ventilator dependence/support. Among these, only two postoperative complication outcomes (i.e., prolonged air leakage and wound infection) include three studies reporting sufficient data. The remaining ones include only zero, one, or two studies (Table III). Also, as it is not possible to conduct a meta-analysis and meta-regression with less than three studies and subgroup analysis with three or less than three studies [32-34], so the meta-analysis and meta-regression were performed for only prolonged air leakage and wound infection where the list in Table III was excluded; and subgroup analyses were performed for none of the postoperative complication outcomes listed in Table III or for prolonged air leakage and wound infection. For both procedures, the results of random-effects meta-analysis for the seven outcomes will be presented later. Moreover, the results of random-effects meta-regression based on published year, sample size difference, mean hospital stay difference, latitude, and longitude will also be demonstrated. Finally, the subgroup analyses based on sample size, continents, and published year will be presented.

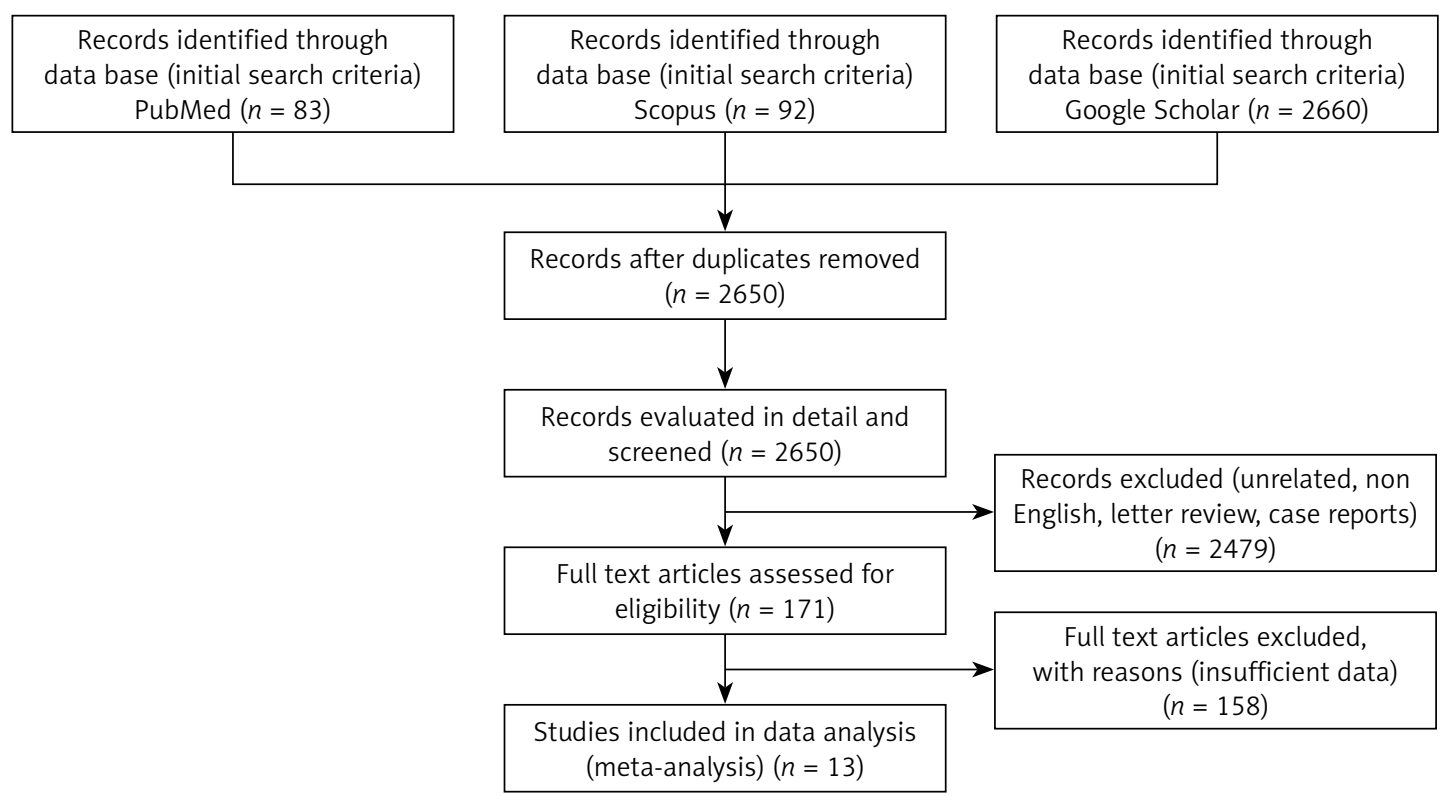

Figure 1. PRISMA flow diagram for illustrating the flow of article selection in the systematic review for the metaanalysis procedure 
Table I. Demographic characteristics of patients in studies treated by open decortication procedure ( $n=13$ studies)

\begin{tabular}{|lccccccccc|}
\hline Study & Year & Patients & $\begin{array}{c}\text { Prolonged } \\
\text { air } \\
\text { leakage }\end{array}$ & $\begin{array}{c}\text { Failure or } \\
\text { converted } \\
\text { operations }\end{array}$ & Death Recurrence & $\begin{array}{c}\text { Hospital } \\
\text { stay [days] }\end{array}$ & $\begin{array}{c}\text { Time of } \\
\text { operations } \\
\text { [min] }\end{array}$ & $\begin{array}{c}\text { Wound } \\
\text { infec- } \\
\text { tion }\end{array}$ \\
\hline Mark & 2012 & 227 & NS & 0 & 0 & NS & $10 \pm 3.625$ & NS & NS \\
\hline Cardillo & 2009 & 123 & NS & 6 & 0 & 2 & $10 \pm 7.8$ & $79.7 \pm 6.8$ & NS \\
\hline Mingarini & 2012 & 93 & 6 & 18 & 13 & 6 & $9(7-14)$ & $198 \pm 82.6$ & 3 \\
\hline Chan & 2007 & 36 & NS & NS & 0 & 0 & $21 \pm 14.2$ & $228 \pm 84$ & NS \\
\hline Lardinois & 2005 & 150 & NS & 0 & 6 & 4 & NS & NS & NS \\
\hline Waller & 2001 & 23 & NS & 0 & 1 & 0 & $8.7 \pm 0.9$ & $128.2 \pm 7.9$ & NS \\
\hline Chung & 2014 & 8 & NS & 0 & 0 & 0 & $19 \pm 12.82$ & $299.38 \pm 74.66$ & NS \\
\hline Lawrence & 1997 & 12 & NS & 0 & 0 & 0 & $10.3 \pm 2.1$ & NS & NS \\
\hline Podbiliski & 2000 & 14 & NS & 0 & 0 & 0 & $16.8 \pm 10.2$ & $125 \pm 71.7$ & NS \\
\hline Wassem & 2016 & 12 & 2 & 0 & 0 & 0 & $21.82 \pm 16.35$ & $222.42 \pm 51.95$ & 2 \\
\hline Luh & 2005 & 40 & NS & 0 & 4 & 0 & $20.1 \pm 12.5$ & NS & NS \\
\hline Bačic & 2015 & 15 & NS & 0 & 0 & 0 & $9 \pm 1.75$ & NS & NS \\
\hline Tong & 2010 & 94 & 17 & 10 & 4 & 10 & $9.7 \pm 10.1$ & $15.5 \pm 0.01$ & 0 \\
\hline
\end{tabular}

NS - not stated.

Table II. Demographic characteristics of patients in studies treated by VATS procedure ( $n=13$ studies)

\begin{tabular}{|lcccccccccc|}
\hline Study & Year & Patients & $\begin{array}{c}\text { Prolonged } \\
\text { air leakage }\end{array}$ & $\begin{array}{c}\text { Failure or } \\
\text { converted } \\
\text { operations }\end{array}$ & Death Recurrence & $\begin{array}{c}\text { Hospital } \\
\text { stay [days] }\end{array}$ & $\begin{array}{c}\text { Times of } \\
\text { operations } \\
\text { [min] }\end{array}$ & $\begin{array}{c}\text { Wound } \\
\text { infection }\end{array}$ \\
\hline Mark & 2012 & 116 & NS & 17 & 0 & 0 & $7 \pm 2.25$ & NS & NS \\
\hline Cardillo & 2009 & 185 & NS & 11 & 0 & 2 & $8.6 \pm 1.8$ & $70 \pm 7.4$ & NS \\
\hline Mingarini & 2012 & 113 & 7 & 28 & 18 & 13 & $10 \pm 1.5$ & $202.7 \pm 90.8$ & 4 \\
\hline Chan & 2007 & 41 & NS & NS & 0 & 0 & $16 \pm 6.5$ & $150 \pm 57.6$ & NS \\
\hline Lardinois & 2005 & 178 & NS & 79 & 7 & 4 & NS & NS & NS \\
\hline Waller & 2001 & 39 & NS & 23 & 0 & NS & $5.2 \pm 0.6$ & $86.2 \pm 10.4$ & NS \\
\hline Chung & 2014 & 14 & NS & 1 & 0 & NS & $13.5 \pm 6.38$ & $138.57 \pm 52.057$ & NS \\
\hline Lawrence & 1997 & 30 & NS & NS & 0 & NS & $5.3 \pm 4$ & NS & NS \\
\hline Podbiliski & 2000 & 16 & NS & 2 & 0 & NS & $11.4 \pm 6.5$ & $76.2 \pm 30.7$ & NS \\
\hline Wassem & 2016 & 63 & 1 & 12 & 2 & NS & $9.65 \pm 4.1$ & $144.55 \pm 67.15$ & 2 \\
\hline Luh & 2005 & 234 & NS & 40 & 4 & 0 & $7.2 \pm 3.2$ & NS & NS \\
\hline Bačić & 2015 & 17 & NS & 2 & 0 & 0 & $5 \pm 1.5$ & NS & NS \\
\hline Tong & 2010 & 326 & 21 & 37 & 24 & 0 & $7 \pm 13.7$ & $97 \pm 0.01$ & 5 \\
\hline
\end{tabular}

NS - not stated.

\section{Meta-analysis models}

There were no significant differences in postoperative prolonged air leakage results of open thoracotomy decortication and VATS (Figure $2 \mathrm{~A}$, Table IV). Moderate heterogeneity was detected among the included studies (Table V).

There were no significant differences in mortality results of open thoracotomy decortication and
VATS (Figure 2 B, Table IV). Moderate heterogeneity was detected among the included studies (Table V).

Also, there were no significant differences in recurrence results of open thoracotomy decortication and VATS (Figure 2 C, Table IV). Substantial heterogeneity was detected among the included studies (Table V).

The failure and conversion rate was significantly higher in VATS compared to that of open tho- 


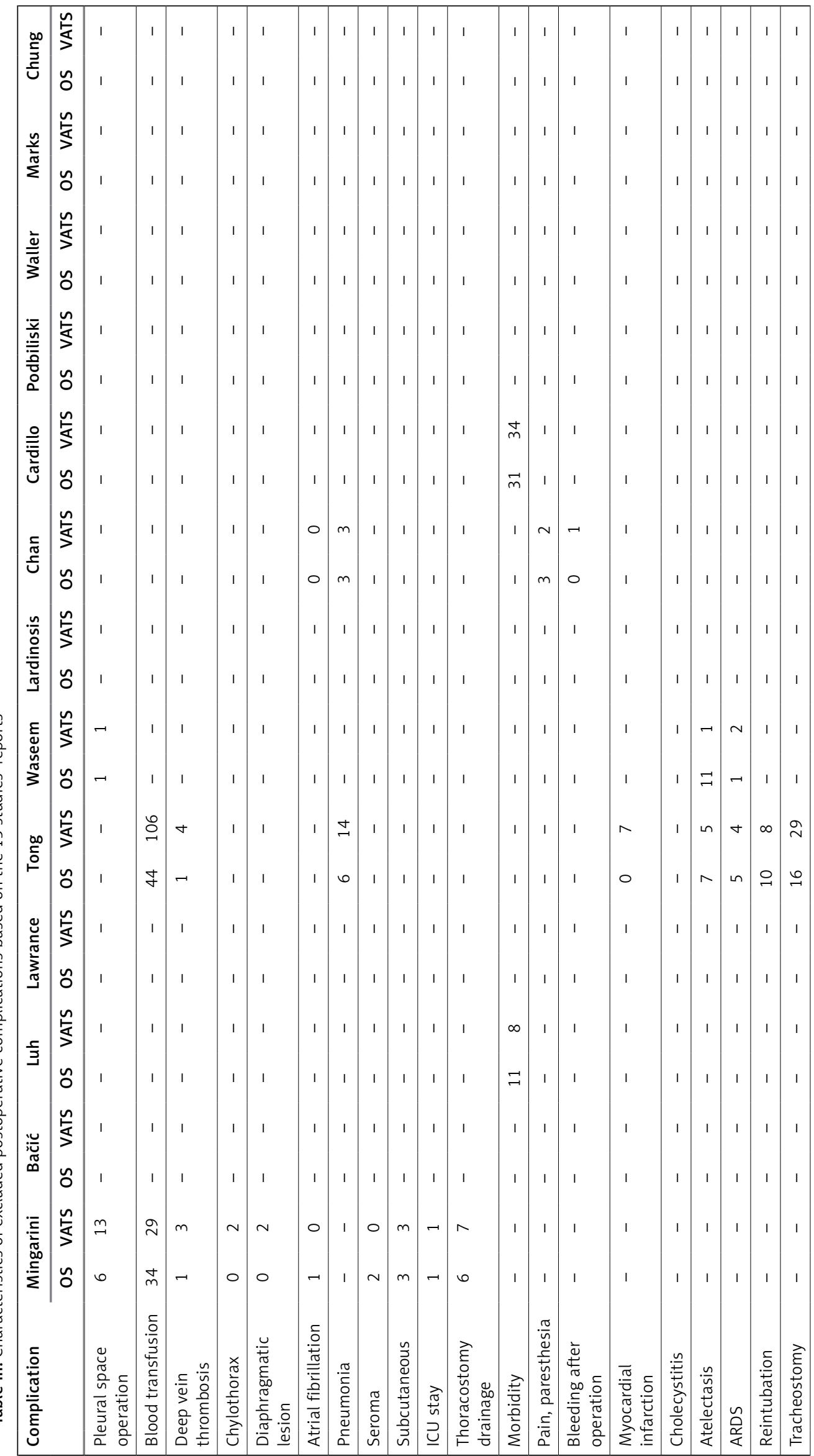




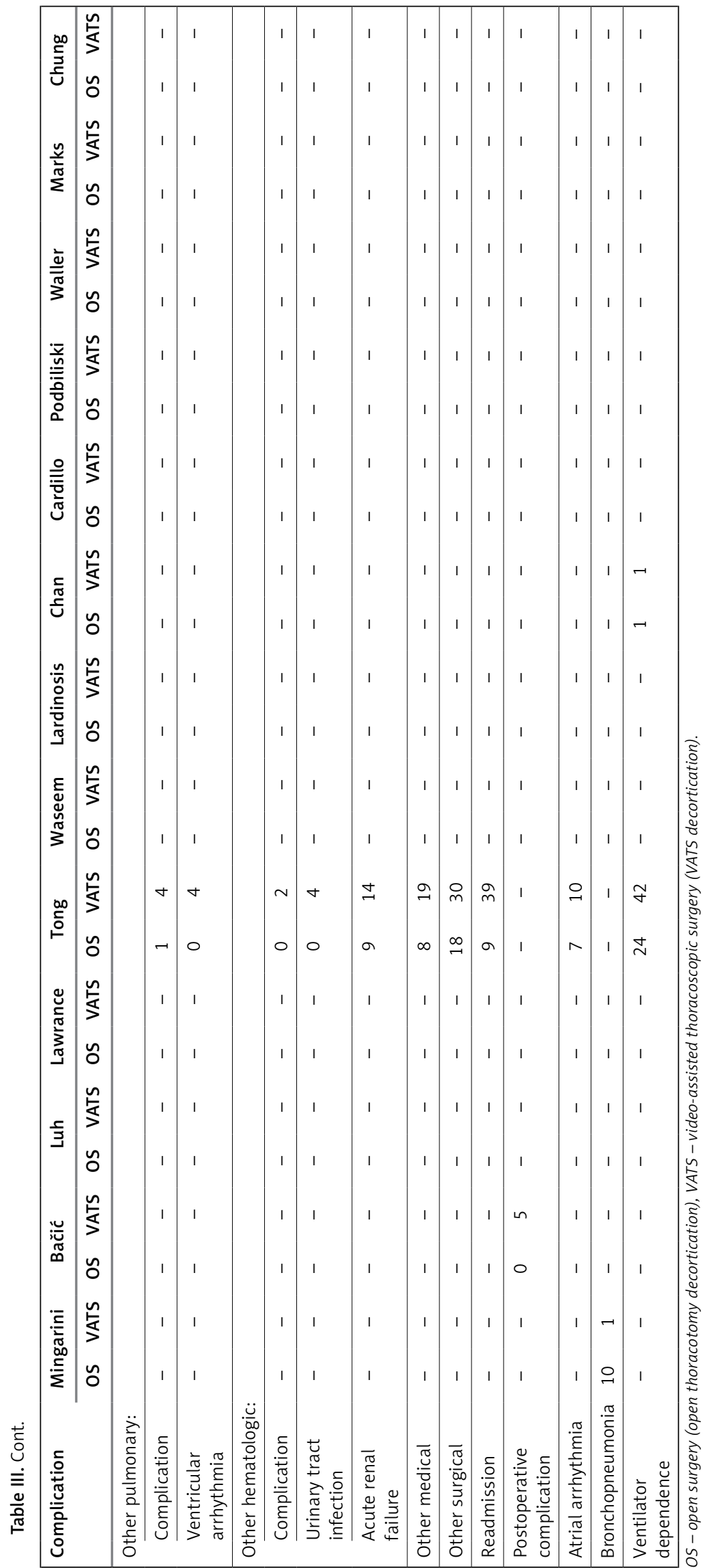


A

Meta-analysis of odds ratio with $95 \%$ confidence interval
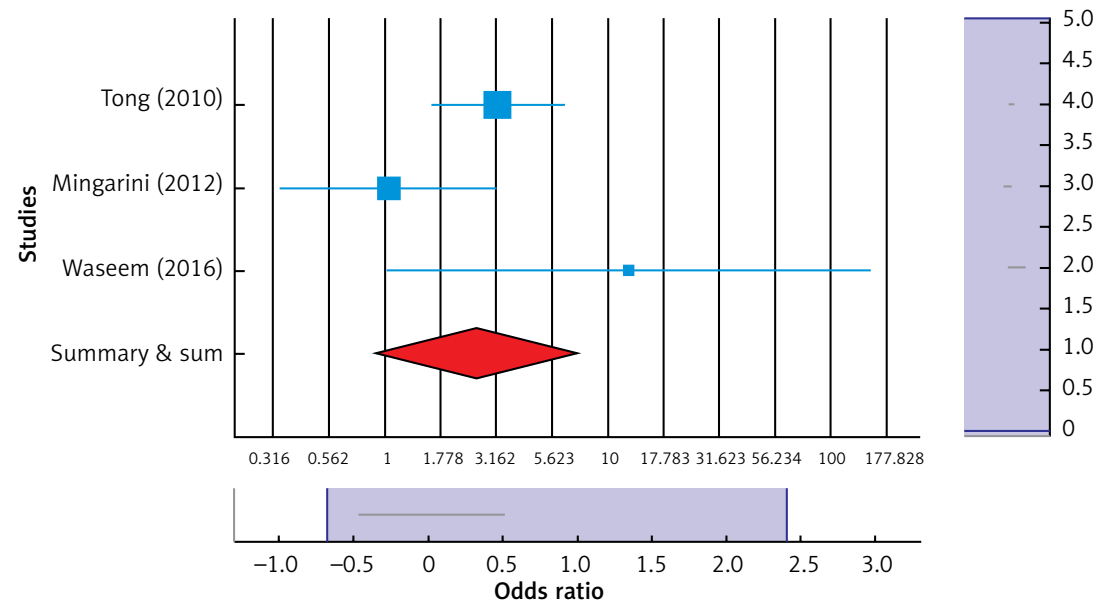

B

Meta-analysis of odds ratio with $95 \%$ confidence interval
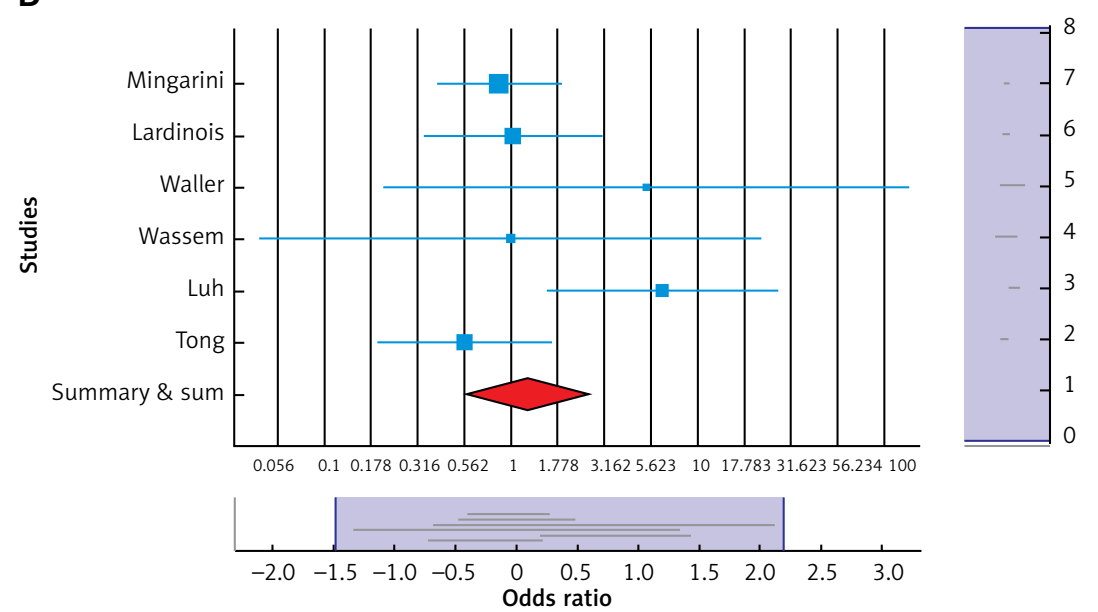

C

Meta-analysis of odds ratio with $95 \%$ confidence interval
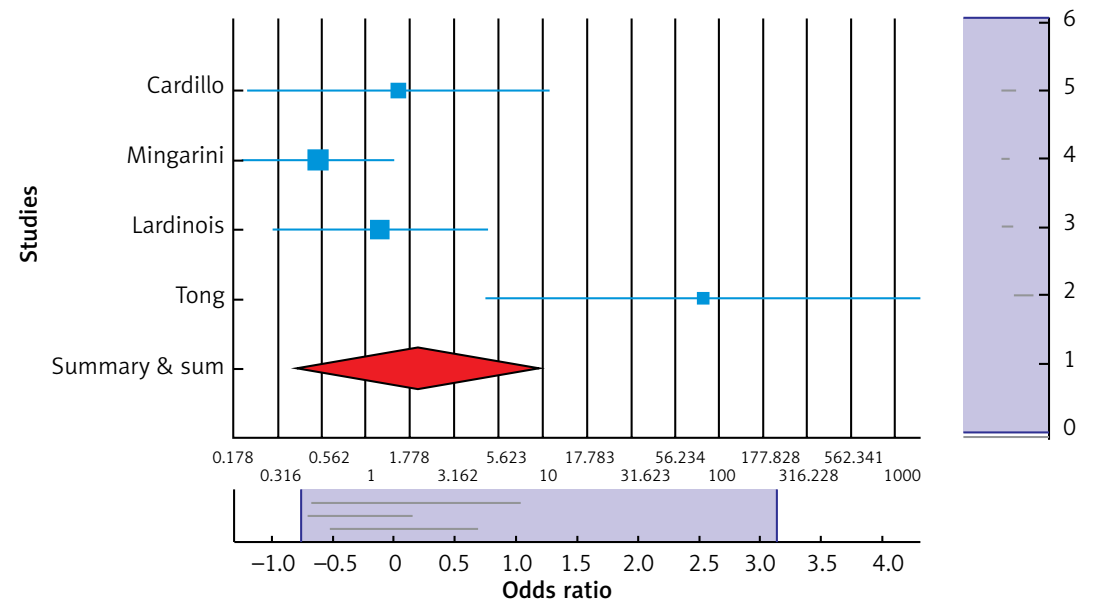

D

Meta-analysis of odds ratio with $95 \%$ confidence interval
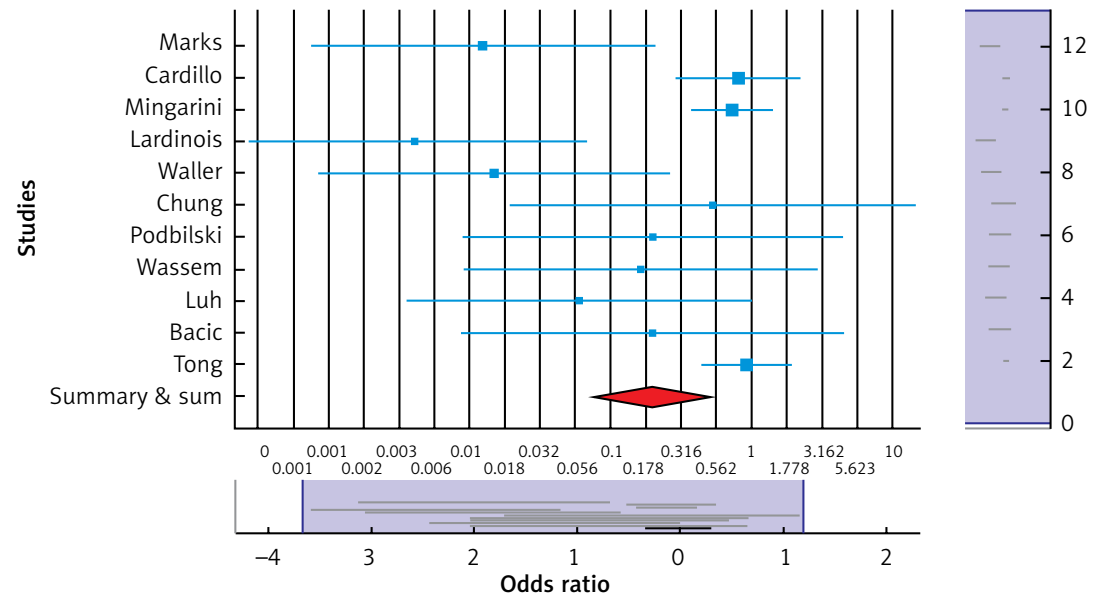

Figure 2. Forest plots using odds ratio for postoperative prolonged air leakage (A), mortality (B), recurrence (C), failure or converted operations (D) 
E Meta-analysis of Hedge $\mathrm{g}$ with $95 \%$ confidence interval
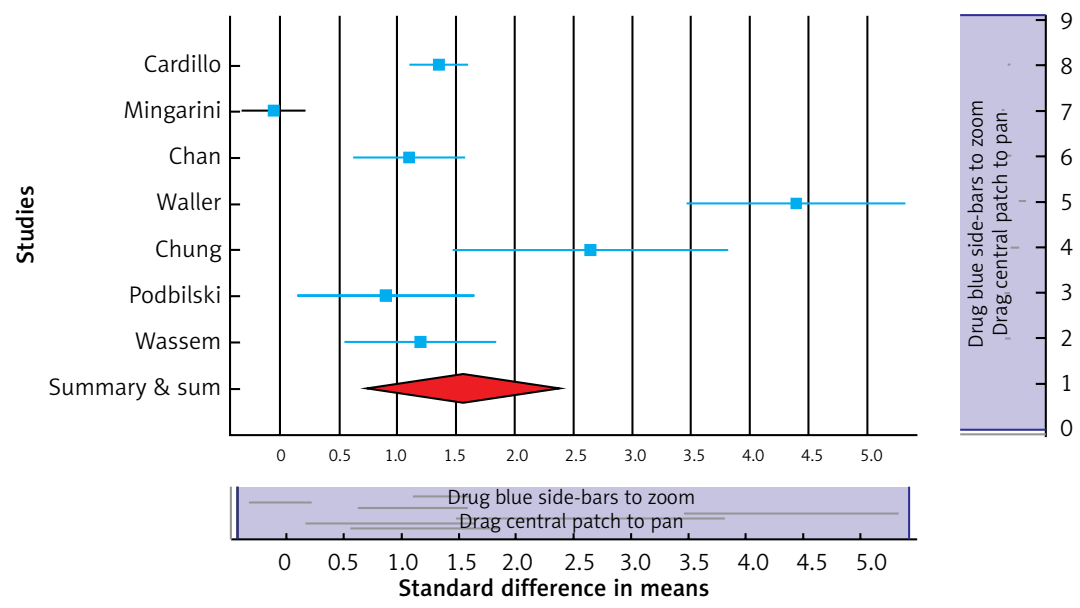

$\mathbf{F}$ Meta-analysis of Hedge $\mathrm{g}$ with $95 \%$ confidence interval
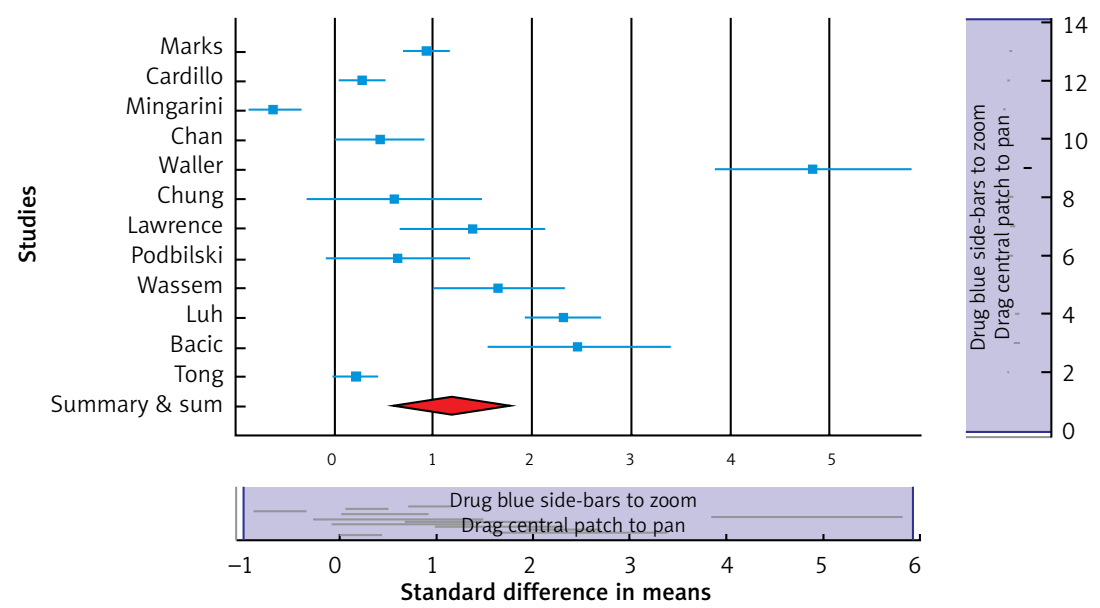

G

Meta-analysis of odds ratio with $95 \%$ confidence interval

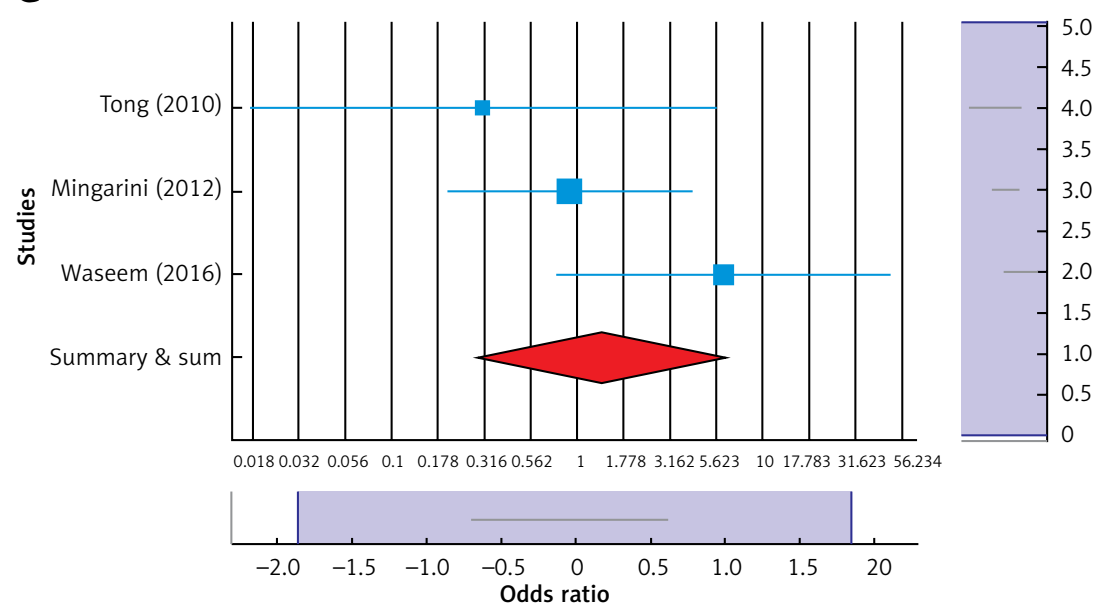

Figure 2. Cont. Forest plots using standard mean difference (SMD) for times of operation (E), hospital stay (F), and wound infection $(\mathbf{G})$

racotomy decortication (Figure $2 \mathrm{D}$, Table IV). The studies show a significant degree of heterogeneity (Table V).

Mean times of operations in open thoracotomy decortication were significantly longer than those of VATS (Figure 2 E, Table IV). Considerable, sig- nificant heterogeneity was detected among the included studies (Table V).

Postoperative hospital stays of open thoracotomy decortications were longer than those of VATS (Figure 2 F, Table IV). Considerable heterogeneity was detected among the included studies (Table V). 
Table IV. Detailed meta-analysis model with $95 \%$ confidence interval between two procedures

\begin{tabular}{|lcccccccc|}
\hline Variable & OR & LL & UL & z-value & $P$-value & V & SMD & SE \\
\hline $\begin{array}{l}\text { Prolonged air } \\
\text { leakage }\end{array}$ & 2.564 & 0.904 & 7.274 & 1.770 & 0.077 & & & \\
\hline Mortality & 1.234 & 0.591 & 3.579 & 0.560 & 0.576 & & & \\
\hline Recurrence & 1.962 & 0.409 & 9.424 & 0.842 & 0.4 & & & \\
\hline $\begin{array}{l}\text { Failure or } \\
\text { conversion rate }\end{array}$ & 0.198 & 0.077 & 0.51 & -3.352 & $8.012 e^{-4}$ & & & \\
\hline Time of operation & & 0.749 & 2.381 & 3.757 & $<0.001$ & 0.173 & 1.565 & 0.416 \\
\hline Hospital stay & & 0.622 & 1.755 & 4.113 & $<0.001$ & 0.084 & 1.189 & 0.289 \\
\hline Wound infection & 1.363 & 0.294 & 6.322 & 0.396 & 0.0692 & & & \\
\hline
\end{tabular}

Table V. Heterogeneity meta-analysis model

\begin{tabular}{|c|c|c|c|c|c|}
\hline Variable & $Q$ & $\mathrm{~d} f$ & $P$-value & $I^{2}$ & $\Gamma^{2}$ \\
\hline $\begin{array}{l}\text { Prolonged air } \\
\text { leakage }\end{array}$ & 4.385 & 2 & 0.112 & 54.395 & 0.446 \\
\hline Mortality & 8.626 & 5 & 0.125 & 42.038 & 0.324 \\
\hline Recurrence & 10.877 & 3 & 0.012 & 72.418 & 1.748 \\
\hline $\begin{array}{l}\text { Failure or } \\
\text { conversion rate }\end{array}$ & 31.763 & 10 & $4.384 \mathrm{e}^{-4}$ & 68.517 & 1.298 \\
\hline Time of operation & 122.944 & 6 & $<1 \mathrm{e}^{-16}$ & 95.12 & 1.091 \\
\hline Hospital stay & 0.273 & 11 & $<1 \mathrm{e}^{-16}$ & 95.976 & 0.906 \\
\hline Wound infection & 3.286 & 2 & 0.193 & 39.145 & 0.731 \\
\hline
\end{tabular}

There were no significant differences in wound infection results of open thoracotomy decortication and VATS (Figure 2 G, Table IV). Moderate heterogeneity was detected among included studies (Table V), but it was not significant.

\section{Meta-regression models}

For the postoperative prolonged air leakage outcome (Figure $3 \mathrm{~A}$, Table VI), the results of random-effects model meta-regression based on published year, latitude, sample size difference, and longitude showed that they cannot explain the heterogeneity of the included studies. However, mean hospital stay differences can explain $100 \%$ of heterogeneity $\left(R^{2}=100 \%\right)$. There were no relationships of the published year versus log odds ratio and latitude/ longitude or sample size difference versus log odds ratio; however, a direct relationship was observed between mean hospital stay differences and log OR.

For mortality outcome (Figure $3 \mathrm{~B}$, Table VI), random-effects meta-regression on mean hospital stay differences was not carried out due to insufficient data. The results on published year, latitude, and sample size differences show that they cannot explain the heterogeneity of the included studies; however, the model based on longitude can explain $94 \%$ of heterogeneity $\left(R^{2}=94 \%\right)$.
There were no relationships of published year versus log OR, latitude versus log OR, or sample size differences versus log OR, while there is a direct relation between longitude and log $O R$.

For recurrence outcome (Figure $3 \mathrm{C}$, Table VI) the data for random-effects met-regression based on hospital stay differences was not enough. Moreover, the results of random-effects meta-regression based on sample size difference can explain $100 \%$ of heterogeneity $\left(R^{2}=100 \%\right)$ by an inverse relationship with recurrence. Moreover, the meta-regression models based on published year, latitude, and longitude cannot explain the heterogeneity as there were no relationships between $\log \mathrm{OR}$ and the rest of the parameters.

For failure or converted operations outcome (Figure 3 D, Table VI), the data for hospital stay differences were not enough. The random-effects meta-regression based on published year, sample size difference, latitude and longitude cannot explain the heterogeneity. Moreover, there were no relationships between log OR and the other parameters. As the $p$-values were not significant.

For times of operations outcome (Figure $3 \mathrm{E}$, Table $\mathrm{VI}$ ), the results of random-effects meta-regression based on published year, sample size difference, and longitude cannot explain the heterogeneity of studies according to the non-significant 
A
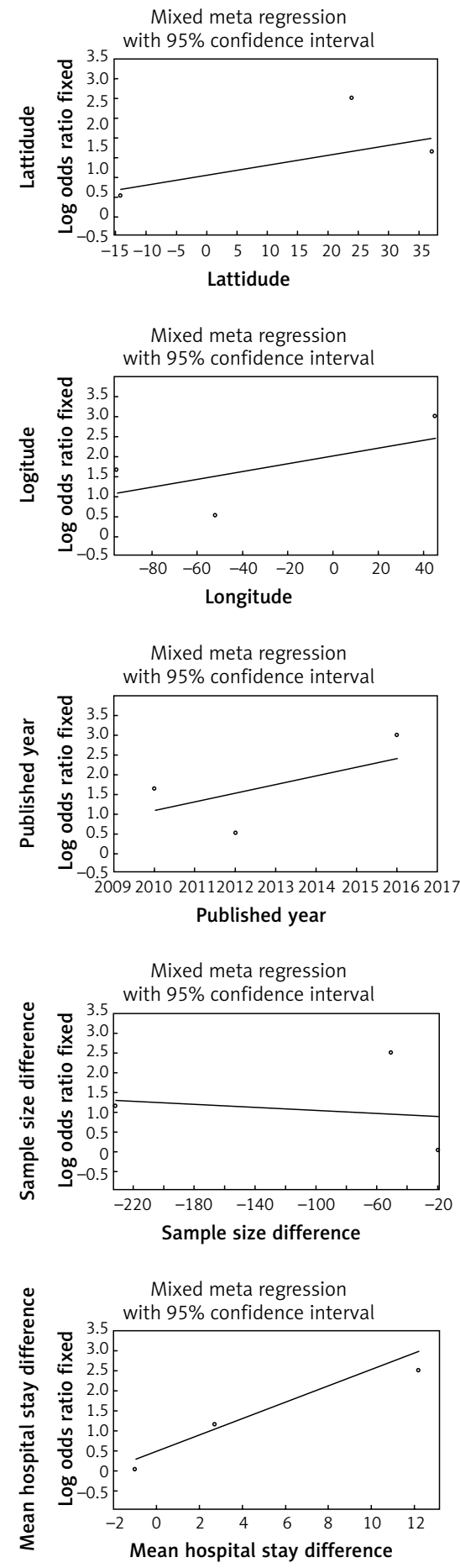

B
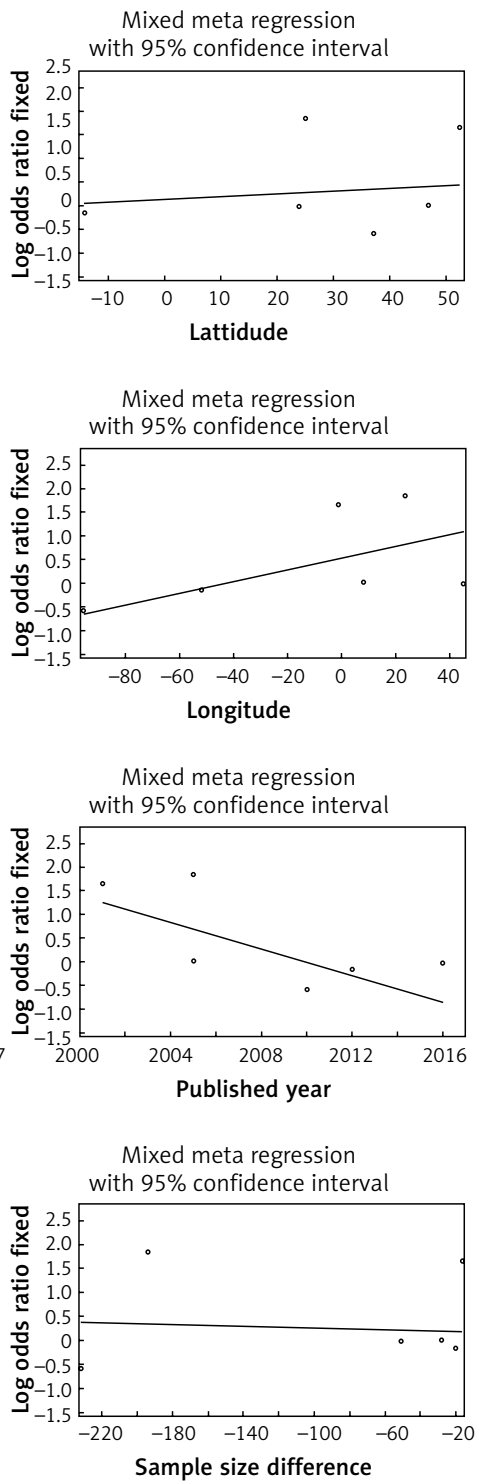

\section{C}
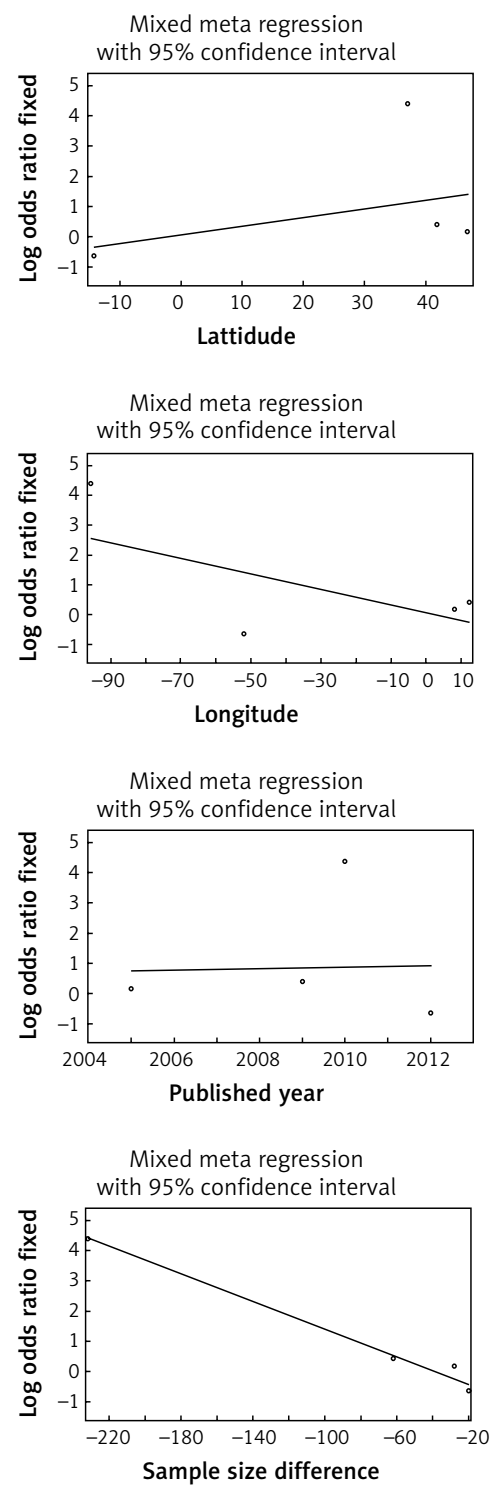

Figure 3. Meta regression based on sample size, continent, latitude, longitude, and published year between two procedures for postoperative prolonged air leakage (A), mortality (B), recurrence (C), failure or converted operations (D), time of operation (E), and postoperative hospital stay ( $F)$

$p$ value, and hence, there were no relationships between SMD of times of operations and the other parameters. Furthermore, random-effects meta-regression based on latitude can explain $47.6 \%$ of heterogeneity, suggesting a direct relationship between latitude and SMD of times of operations in the two procedures. Also, SMD of hospital stay can explain $77 \%$ of the heterogeneity, which shows a direct relation between SMD of hospital stay and times of operations in the two procedures.

For hospital stay outcome (Figure $3 \mathrm{~F}$, Table VI), the results of random-effects meta-regression based on published year, sample size difference and longitude cannot explain the heterogene- 
D

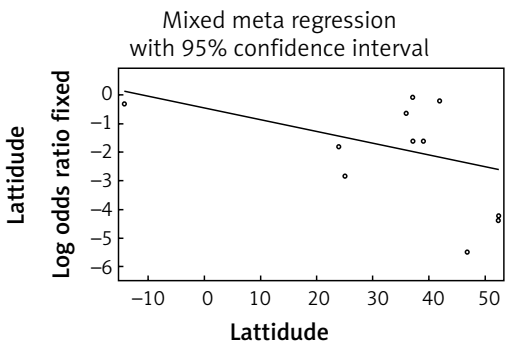

Mixed meta regression
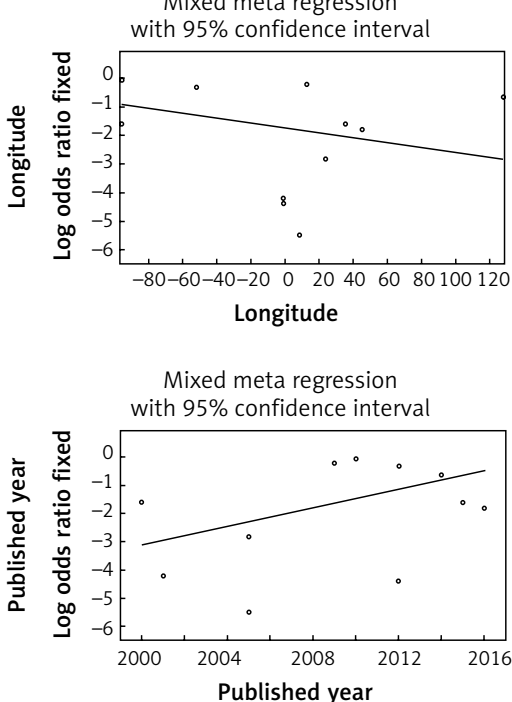

Mixed meta regression

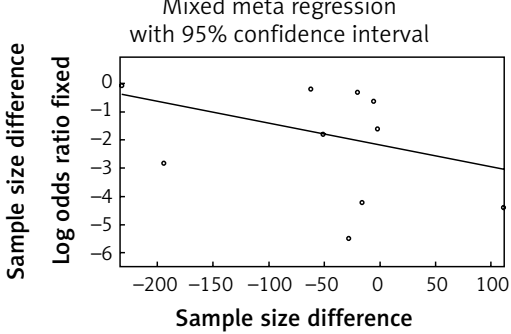

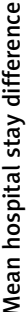

\section{$\mathrm{E}$}

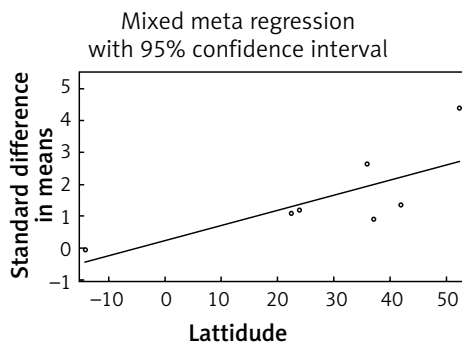

Mixed meta regression
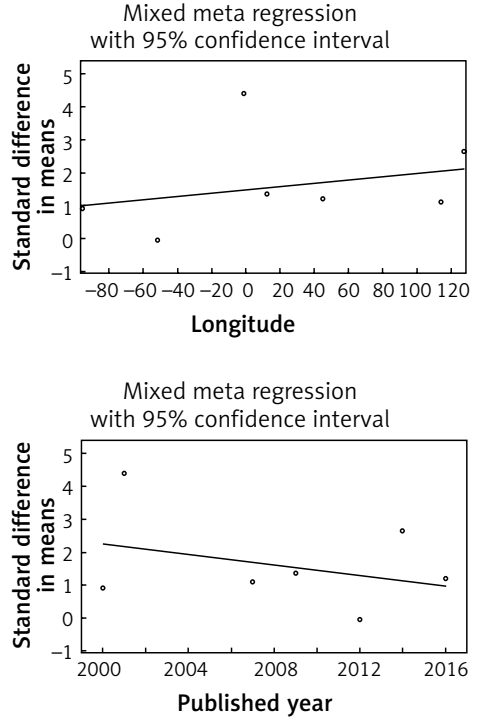

Mixed meta regression

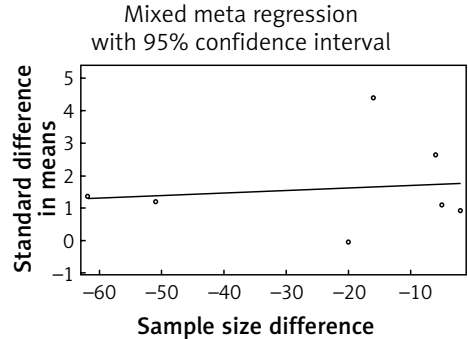

Sample size difference

Mixed meta regression

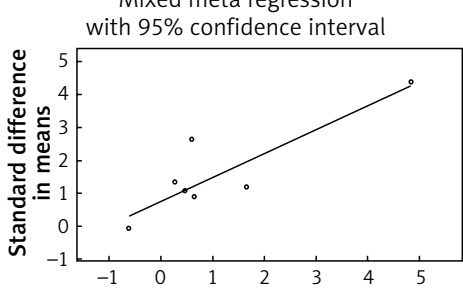

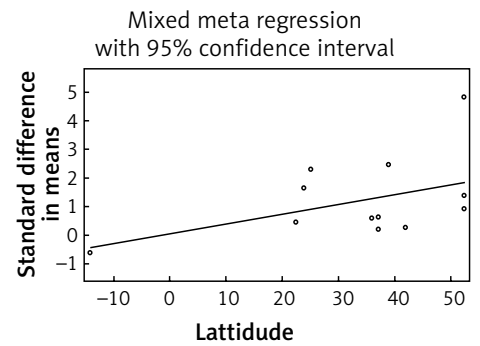

Mixed meta regression with $95 \%$ confidence interval
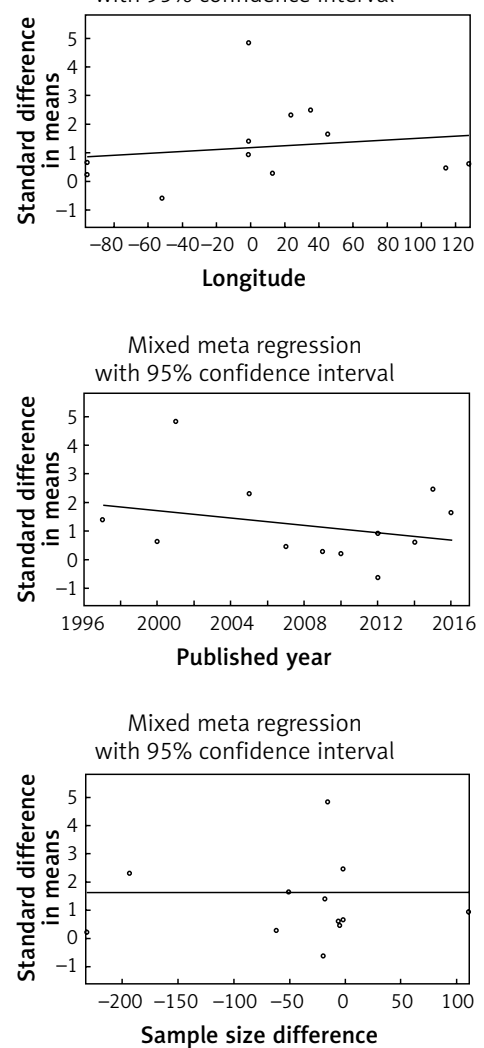

Mean hospital stay difference

Figure 3. Cont. Meta regression based on sample size, continent, latitude, longitude, and published year between two procedures for postoperative prolonged air leakage (A), mortality (B), recurrence (C), failure or converted operations (D), time of operation (E), and postoperative hospital stay $(\mathbf{F})$

ity, since there was no relation between SMD of hospital stay in the two procedures and other parameters. Moreover, random-effects meta-regression based on latitude can only explain $5.29 \%$ of heterogeneity $\left(R^{2}=5.29 \%\right)$, suggesting a direct relationship between latitude and SMD of hospital stay in the two procedures.
Additionally, for 13 studies, subgroup analysis and the heterogeneity subgroup analysis of the 7 outcomes based on sample size, continent, and published year were performed.

For wound infection (Table VI), the results of random-effects meta-regression based on published year, sample size difference, latitude, lon- 
Table VI. Meta-regression model

\begin{tabular}{|c|c|c|c|}
\hline Meta-regression & Slope & $P$-value & $R^{2}$ \\
\hline \multicolumn{4}{|l|}{ Prolonged air leakage: } \\
\hline Published year & 0.2203 & 0.5185 & \\
\hline Latitude & 0.0254 & 0.3077 & \\
\hline Longitude & 0.0097 & 0.4980 & \\
\hline Sample size diff & -0.0019 & 0.8400 & \\
\hline $\begin{array}{l}\text { Mean hospital stay } \\
\text { difference }\end{array}$ & 0.2045 & 0.0468 & 0.000 \\
\hline \multicolumn{4}{|l|}{ Mortality: } \\
\hline Published year & -0.1408 & 0.1193 & \\
\hline Latitude & 0.0057 & 0.7688 & \\
\hline Sample size diff & $-9.459 e^{-4}$ & 0.8429 & \\
\hline Longitude & 0.0124 & 0.0389 & 0.0196 \\
\hline \multicolumn{4}{|l|}{ Recurrence: } \\
\hline Sample size diff & -0.02292 & 0.00129 & 0.000 \\
\hline Published year & 0.0252 & 0.953 & \\
\hline Latitude & 0.0287 & 0.4488 & \\
\hline Longitude & -0.0258 & 0.2752 & \\
\hline \multicolumn{4}{|l|}{ Failure or conversion: } \\
\hline Published year & 0.1641 & 0.1142 & \\
\hline Sample size diff & -0.0077 & 0.1704 & \\
\hline Latitude & -0.0414 & 0.1296 & \\
\hline Longitude & -0.0085 & 0.2967 & \\
\hline \multicolumn{4}{|l|}{ Times of operation: } \\
\hline Published year & -0.0795 & 0.253 & \\
\hline Sample size diff & 0.0076 & 0.7333 & \\
\hline Longitude & 0.0049 & 0.373 & \\
\hline Latitude & 0.047 & 0.002 & 0.5715 \\
\hline $\begin{array}{l}\text { Hospital stay } \\
\text { difference (SMD) }\end{array}$ & 0.7276 & $<0.001$ & 0.24855 \\
\hline \multicolumn{4}{|l|}{ Hospital stay: } \\
\hline Published year & 0.0648 & 0.1755 & \\
\hline Sample size diff & 0.0002 & 0.9572 & \\
\hline Longitude & 0.0032 & 0.4567 & \\
\hline Latitude & 0.0344 & 0.027 & 0.85806 \\
\hline \multicolumn{4}{|l|}{ Wound infection: } \\
\hline Published year & 0.488 & 0.0700 & \\
\hline Latitude & 0.0003 & 0.9950 & \\
\hline Longitude & 0.0205 & 0.0704 & \\
\hline Sample size diff & 0.0080 & 0.4689 & \\
\hline $\begin{array}{l}\text { Mean hospital stay } \\
\text { difference }\end{array}$ & 0.1503 & 0.1311 & \\
\hline
\end{tabular}

gitude, and mean hospital stay cannot explain the heterogeneity. Additionally, there were no relationships between log OR and the other parameters.

\section{Subgroup analysis results}

Subgroup analyses of postoperative prolonged air leakage outcome and wound infection as well as other remaining postoperative outcomes (Table III) between VATS and open decortication according to the sample size, the continents (i.e., America, Asia, and Europe), and the published year were not performed since the number of studies should be more than three [33].

Subgroup analyses of mortality outcome according to sample size and continent were not performed as the number of studies was less than 3 in these subgroups. Moreover, the subgroup analyses of the published year according to subgroup A, subgroup B, and overall show no differences in outcome of mortality when applying both treatment procedures (Figure $4 \mathrm{D}$ ). Heterogeneity subgroup analyses in subgroups $A$ and $B$ show substantial and no heterogeneity, respectively. Hence, the subgroup analysis of published year $\left(Q_{\text {between }}=3.415, \mathrm{~d} f=1, p=0.065\right)$ cannot explain the variance within the studies (listed in Tables VII and VIII).

Again, subgroup analyses of recurrence outcome according to sample size, continent, and published year were not performed since the number of studies in subgroups was less than 3.

The subgroup analyses of failure and converted operations outcome according to sample size in subgroup $A$, subgroup $B$, and overall show no, more, and more failure and converted operations for the VATS procedure, respectively (Figure 4 A). Moreover, heterogeneity subgroup analyses in subgroups $A$ and $B$ show considerable and substantial heterogeneity, respectively. Therefore, subgroup analysis of sample size $\left(Q_{\text {between }}=0.248\right.$, $\mathrm{d} f=1$, and $p=0.619)$ cannot explain the variance within the studies. The subgroup analyses according to the continent (i.e., America, Asia, and Europe), and overall show no, no, more, and more failure for the VATS procedure, respectively (Figure $4 \mathrm{H}$ ). The heterogeneity subgroup analyses according to the continents America, Asia, and Europe show no, no, and considerable heterogeneity, respectively. Thus, the subgroup analyses according to the continent $\left(Q_{\text {between }}=4.647, \mathrm{~d} f=2\right.$, and $p=0.098$ ) cannot explain the variance within the studies. Moreover, the subgroup analyses according to the published year in subgroup $A$, subgroup $B$, and overall show more, no, and more failure rates for the VATS procedure, respectively (Figure $4 \mathrm{E}$ ). The heterogeneity subgroup analyses in subgroups $A$ and $B$ show considerable and moderate heterogeneity, respectively. Thus, subgroup analy- 
ses according to published year $\left(Q_{\text {between }}=1.697\right.$, subgroup B, and overall show no, more and more $\mathrm{d} f=1, p=0.193$ ) cannot explain the variance time of operations considering their SMD values within studies (listed in Tables VII and VIII). for open thoracotomy decortication (Figure 4 B).

The subgroup analyses of duration of oper- The heterogeneity subgroup analyses in subations according to sample size in subgroup $A$, groups $A$ and $B$ show considerable and consider-

A

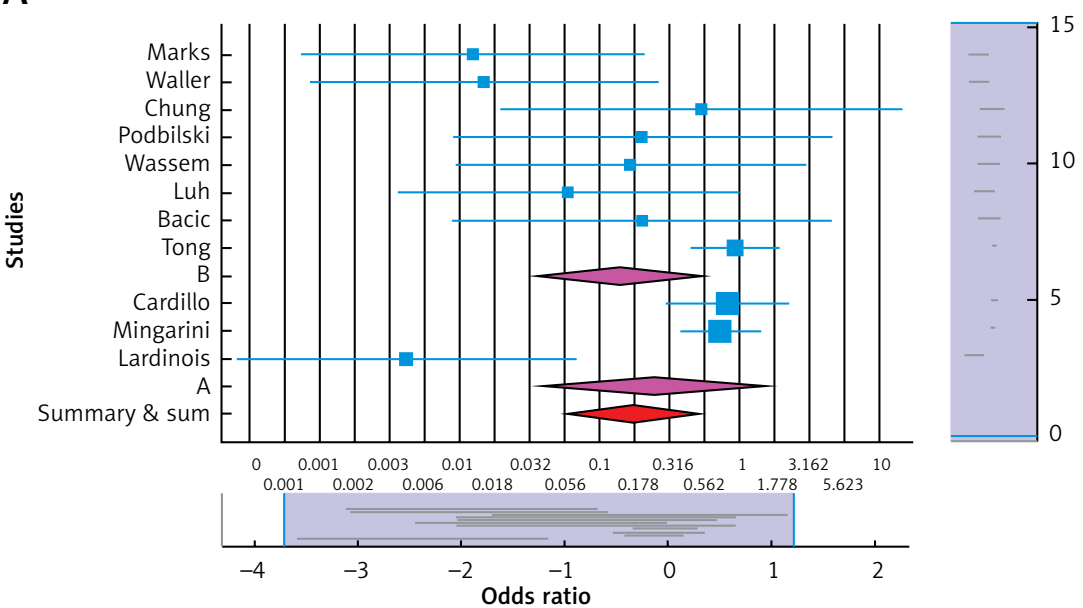

B

Meta-analysis of standard difference in means with $95 \%$ confidence ratio
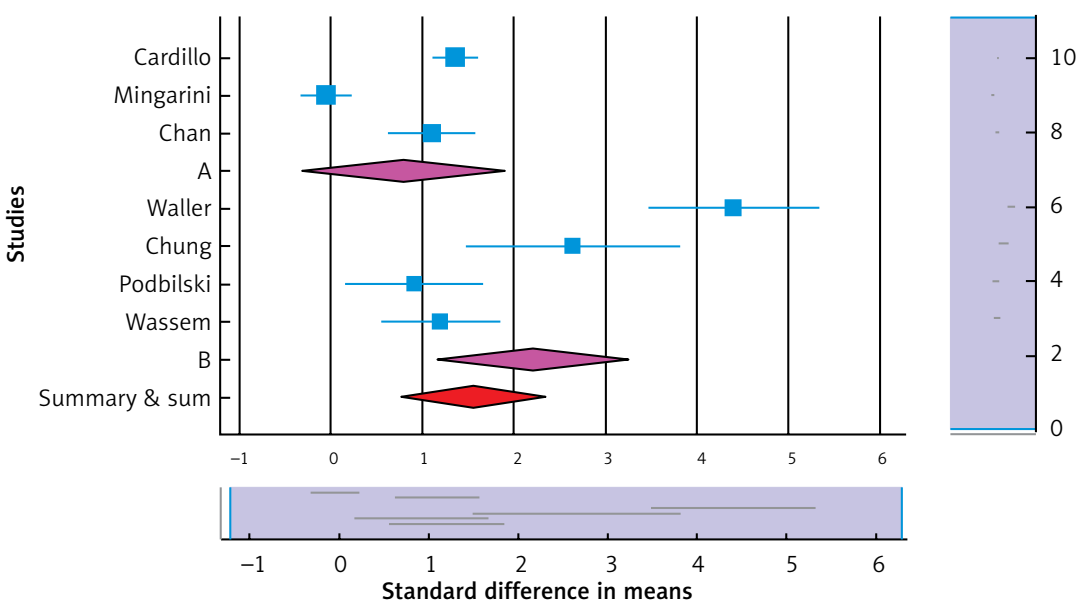

C

Meta-analysis of standard difference in means with $95 \%$ confidence ratio
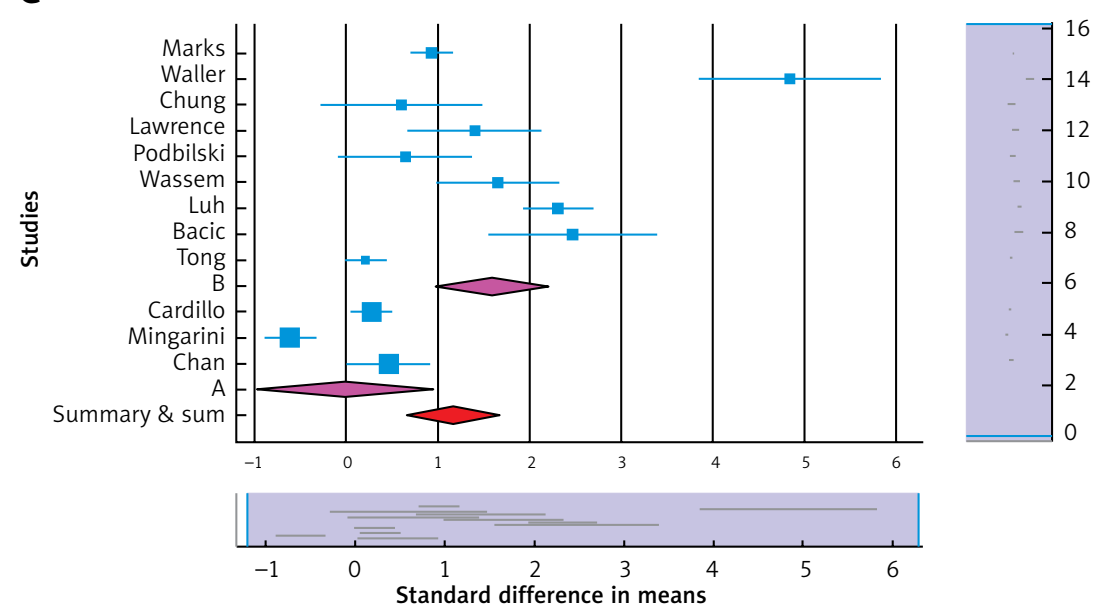

Figure 4. Subgroup analyses of outcomes of studies based on sample size (A-C), published year (D-G), and continent $(\mathrm{H}, \mathrm{I})$ 
able amounts of heterogeneity, respectively. And hence, subgroup analysis of sample size $\left(Q_{\text {b }}\right.$ $=3.207, \mathrm{~d} f=1$, and $p=0.073$ ) cannot explain the variance within studies (listed in Tables III and IV). Subgroup analyses according to the continent were not performed since the number of studies within the subgroups was less than 3. Moreover, the subgroup analyses according to the published year in subgroup $A$, subgroup $B$, and overall show more, no and more taken times of operations con-

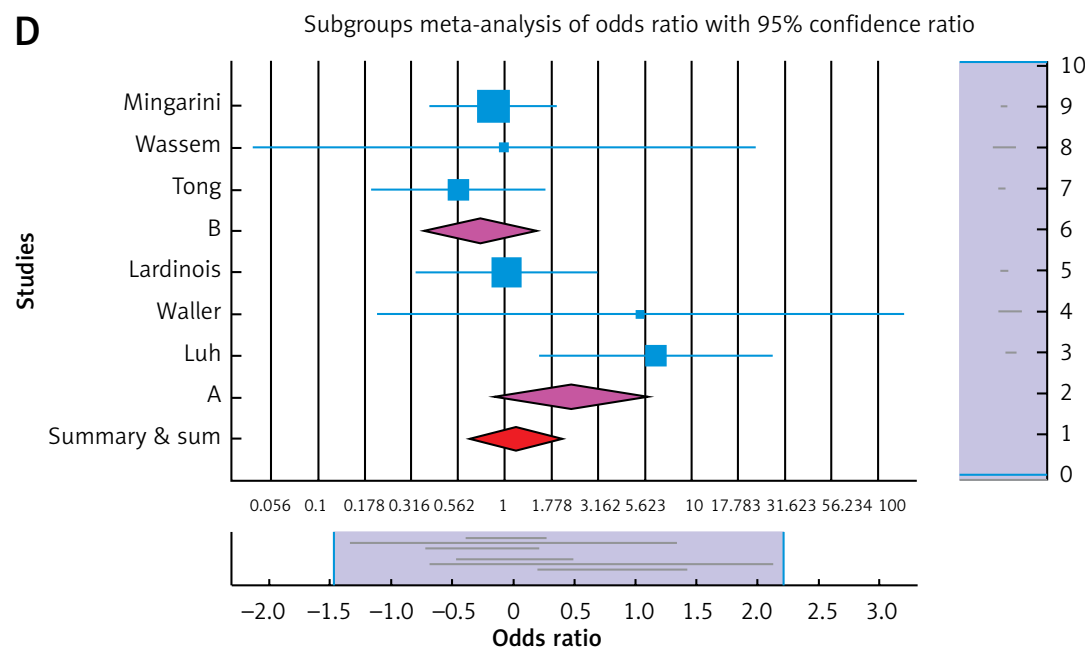

E Subgroups meta-analysis of odds ratio with $95 \%$ confidence ratio

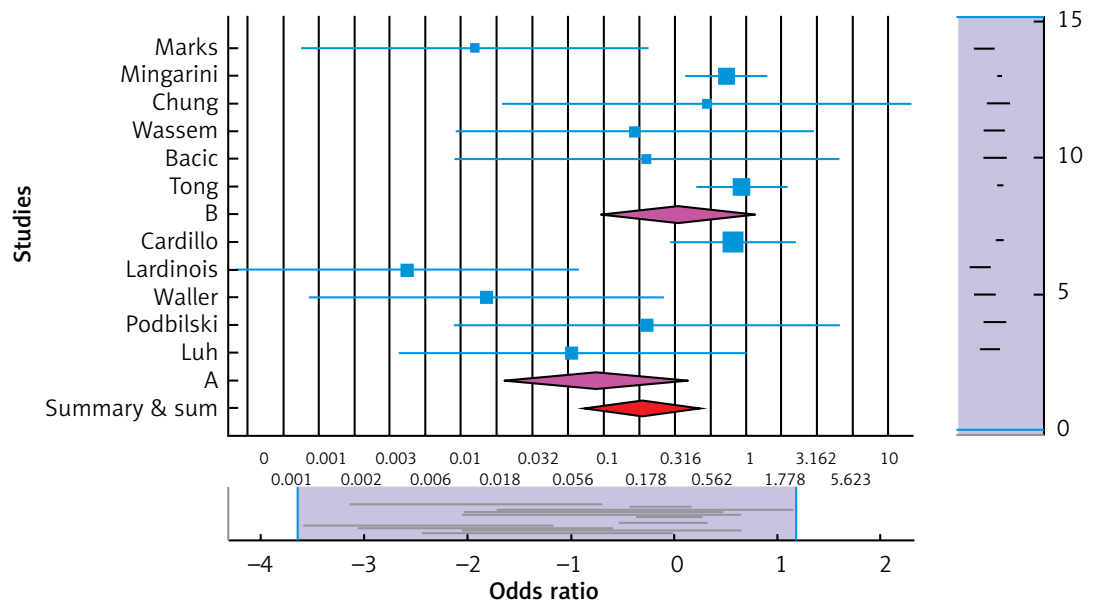

F
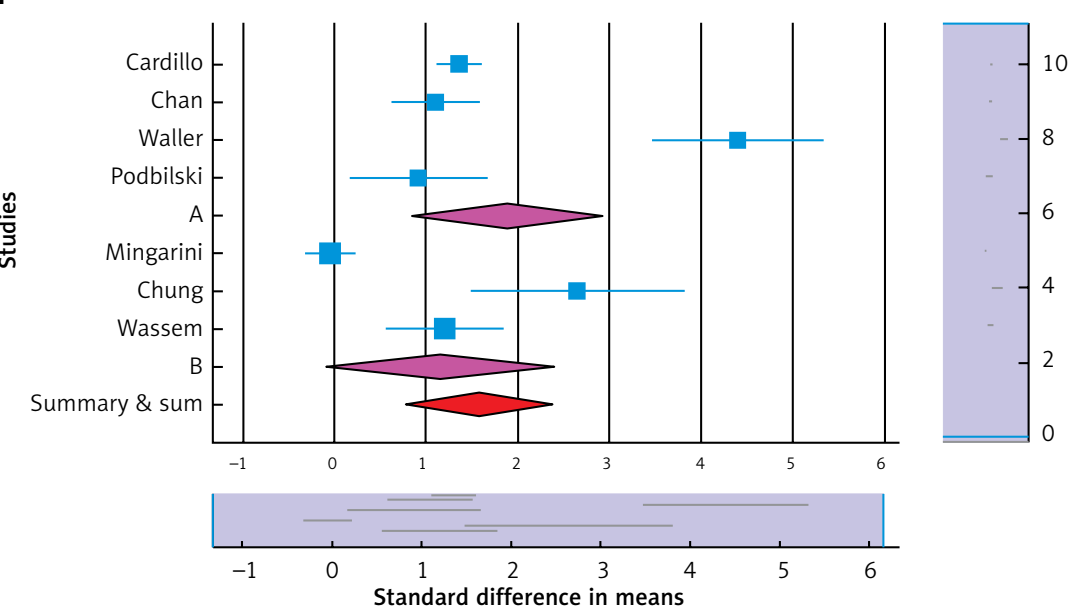

Figure 4. Cont. Subgroup analyses of outcomes of studies based on sample size (A-C), published year (D-G), and continent $(\mathrm{H}, \mathrm{I})$ 
sidering SMD values for open thoracotomy (Figure 4 F). The heterogeneity subgroup analyses according to subgroups $A$ and $B$ show considerable and considerable amounts of heterogeneity, respectively. And hence, the subgroup analyses of the published year $\left(Q_{\text {between }}=0.765, \mathrm{~d} f=1, p=0.382\right)$ cannot explain the variance within studies (listed in Tables VII and VIII).

Subgroup analyses of hospital stay according to sample size in subgroups A, B, and over-
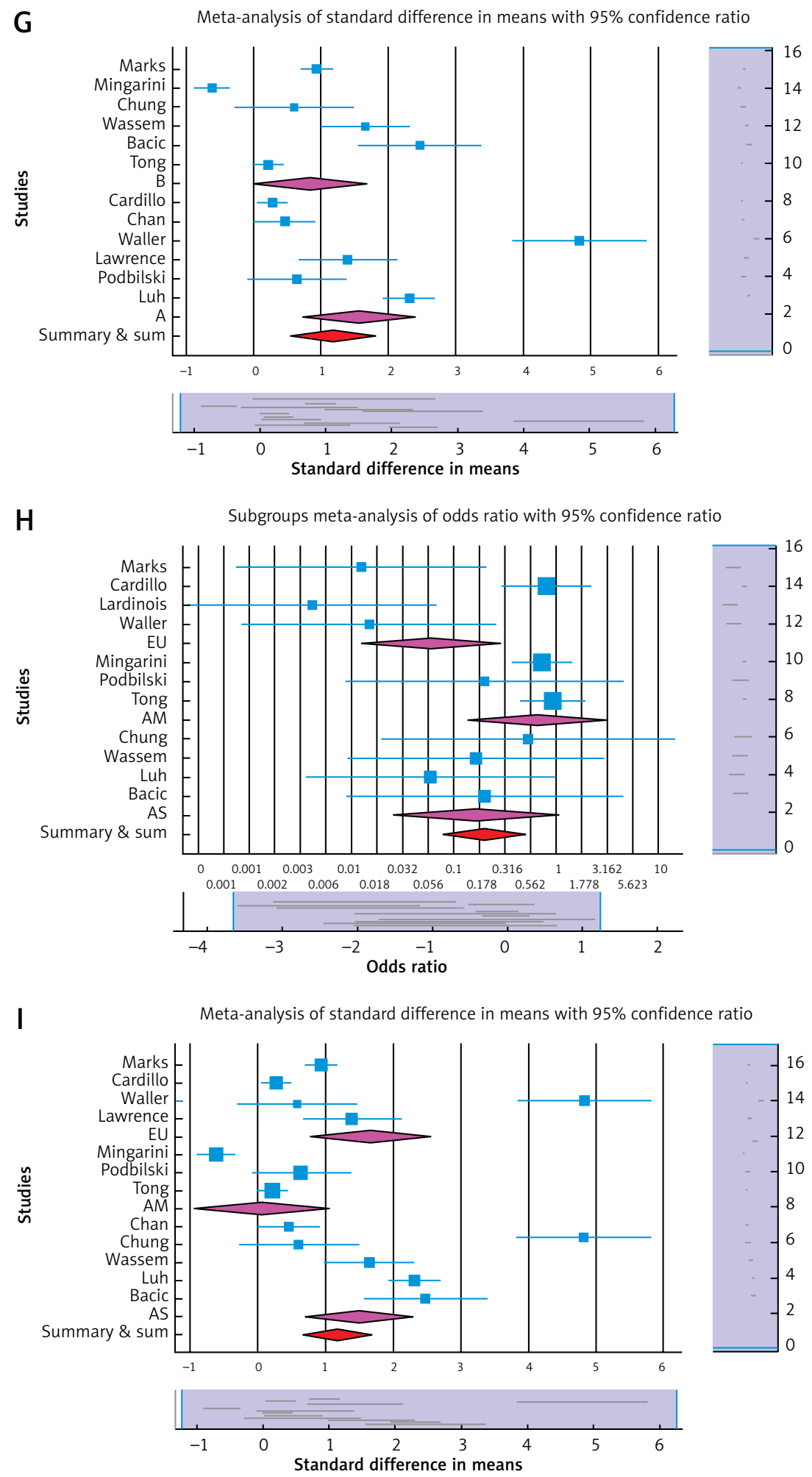

Figure 4. Cont. Subgroup analyses of outcomes of studies based on sample size (A-C), published year (D-G), and continent $(\mathrm{H}, \mathrm{I})$ 
Table VII. Subgroup analysis of mortality, recurrence, failure, operating time, postoperative hospital stay based on sample size, continent, and published year in the 13 studies

\begin{tabular}{|c|c|c|c|c|c|c|c|}
\hline \multirow[t]{10}{*}{ Mortality } & \multirow{3}{*}{$\begin{array}{l}\text { Sample } \\
\text { size }\end{array}$} & $O R_{\mathrm{A}}=0.925$ & \multicolumn{2}{|c|}{$L L=0.283$} & $U L=3.024$ & $Z=-0.128$ & $P=0.898$ \\
\hline & & $O R_{\mathrm{B}}=1.743$ & \multicolumn{2}{|c|}{$L L=0.546$} & $U L=5.564$ & $Z=0.938$ & $P=0.348$ \\
\hline & & $O R_{\text {Overall }}=1.278$ & \multicolumn{2}{|c|}{$L L=0.558$} & $U L=2.928$ & $Z=0.58$ & $P=0.562$ \\
\hline & \multirow[t]{4}{*}{ Continent } & $O R_{\mathrm{Am}}=0.743$ & \multicolumn{2}{|c|}{$L L=0.396$} & $U L=1.393$ & $Z=-0.927$ & $P=0.354$ \\
\hline & & $O R_{\mathrm{AS}}=4.599$ & \multicolumn{2}{|c|}{$L L=1.256$} & $U L=16.843$ & $Z=2.304$ & $P=0.021$ \\
\hline & & $O R_{\mathrm{EU}}=1.21$ & \multicolumn{2}{|c|}{$L L=0.423$} & $U L=3.467$ & $Z=0.356$ & $P=0.722$ \\
\hline & & $O R_{\text {Overall }}=1.085$ & \multicolumn{2}{|c|}{$L L=0.659$} & $U L=1.786$ & $Z=0.319$ & $P=0.75$ \\
\hline & \multirow{3}{*}{$\begin{array}{l}\text { Published } \\
\text { year }\end{array}$} & $O R_{\mathrm{A} 1}=2.276$ & \multicolumn{2}{|c|}{$L L=0.895$} & $U L=5.789$ & $Z=1.726$ & $P=0.084$ \\
\hline & & $O R_{\mathrm{B} 1}=0.741$ & \multicolumn{2}{|c|}{$L L=0.354$} & $U L=1.55$ & $Z=-0.797$ & $P=0.426$ \\
\hline & & $O R_{\text {Overall }}=1.141$ & \multicolumn{2}{|c|}{$L L=0.639$} & $U L=2.037$ & $Z=0.446$ & $P=0.655$ \\
\hline \multirow{10}{*}{$\begin{array}{l}\text { Recur- } \\
\text { rence }\end{array}$} & \multirow{3}{*}{$\begin{array}{l}\text { Sample } \\
\text { size }\end{array}$} & $O R_{\mathrm{A}}=0.783$ & \multicolumn{2}{|c|}{$L L=0.367$} & $U L=1.669$ & $Z=-0.634$ & $P=0.526$ \\
\hline & & $O R_{\mathrm{B}}=81.142$ & \multicolumn{2}{|c|}{$L L=4.707$} & $U L=1398.708$ & $Z=3.026$ & $P=0.002$ \\
\hline & & $O R_{\text {Overall }}=1.064$ & \multicolumn{2}{|c|}{$L L=0.512$} & $U L=2.210$ & $Z=0.165$ & $P=0.869$ \\
\hline & Continent & $O R_{\mathrm{Am}}=4.208$ & \multicolumn{2}{|c|}{$L L=0.186$} & $U L=95.127$ & $Z=0.903$ & $P=0.366$ \\
\hline & & $O R_{\mathrm{AS}}=\mathrm{NA}$ & $L L=$ & NA & $U L=N A$ & $Z=N A$ & $P=\mathrm{NA}$ \\
\hline & & $O R_{\mathrm{EU}}=1.334$ & $L L=0$ & 0.064 & $U L=27.68$ & $Z=0.186$ & $P=0.852$ \\
\hline & & $O R_{\text {Overall }}=2.332$ & $L L=0$ & 0.265 & $U L=20.504$ & $Z=0.763$ & $P=0.445$ \\
\hline & & $O R_{\mathrm{A} 1}=1.334$ & $L L=0$ & 0.064 & $U L=27.68$ & $Z=0.186$ & $P=0.852$ \\
\hline & & $O R_{\mathrm{B} 1}=4.208$ & $L L=0$ & 0.186 & $U L=95.127$ & $Z=0.903$ & $P=0.366$ \\
\hline & & $O R_{\text {Overall }}=2.232$ & $L L=0$ & 0.265 & $U L=20.504$ & $Z=0.763$ & $P=0.445$ \\
\hline Failure & Sample & $O R_{\mathrm{A}}=0.25$ & $L L=C$ & 0.04 & $U L=1.558$ & $Z=-1.484$ & $P=0.138$ \\
\hline & & $O R_{\mathrm{B}}=0.14$ & $L L=0$ & 0.036 & $U L=0.548$ & $Z=-2.827$ & $P=0.005$ \\
\hline & & $O R_{\text {Overall }}=0.172$ & $L L=0$ & 0.058 & $U L=0.514$ & $Z=-3.154$ & $P=0.002$ \\
\hline & Continent & $O R_{\mathrm{Am}}=0.659$ & $L L=0$ & 0.145 & $U L=3.001$ & $Z=-0.539$ & $P=0.59$ \\
\hline & & $O R_{A S}=0.169$ & $L L=0$ & 0.026 & $U L=1.103$ & $Z=-1.858$ & $P=0.063$ \\
\hline & & $O R_{\mathrm{EU}}=0.06$ & $L L=0$ & 0.012 & $U L=0.291$ & $Z=-3.487$ & $P<0.001$ \\
\hline & & $O R_{\text {Overall }}=0.198$ & $L L=0$ & 0.077 & $U L=0.51$ & $Z=-3.355$ & $P<0.001$ \\
\hline & Publi & $O R_{\mathrm{A} 1}=0.088$ & $L L=0$ & 0.019 & $U L=0.402$ & $Z=-3.14$ & $P=0.002$ \\
\hline & & $O R_{\mathrm{B} 1}=0.332$ & $L L=0$ & 0.091 & $U L=1.21$ & $Z=-1.671$ & $P=0.095$ \\
\hline & & $O R_{\text {Overall }}=0.19$ & $L L=0$ & 0.071 & $U L=0.508$ & $Z=-3.31$ & $P<0.001$ \\
\hline Ope & Sample & $S M D_{A}=0.795$ & $S E=0.583$ & $V=0.34$ & $L L=-0.347 \quad U L=1.938$ & $Z=1.365$ & $P=0.172$ \\
\hline & & $S M D_{B}=2.225$ & $S E=0.545$ & $V=0.297$ & $L L=1.156 \quad U L=3.293$ & $Z=4.08$ & $P<0.001$ \\
\hline & & $S M D_{\text {Overall }}=1.557$ & $S E=0.398$ & $V=0.159$ & $L L=0.777 \quad U L=2.338$ & $Z=3.912$ & $P<0.001$ \\
\hline & Continent & $S M D_{A m}=0.404$ & $S E=0.821$ & $V=0.674$ & $L L=-1.205 \quad U L=2.013$ & $Z=0.492$ & $P=0.623$ \\
\hline & & $S M D_{\mathrm{As}}=1.585$ & $S E=0.691$ & $V=0.477$ & $L L=0.231 \quad U L=2.938$ & $Z=2.294$ & $P=0.022$ \\
\hline & & $S M D_{\mathrm{EU}}=2.759$ & $S E=0.831$ & $V=0.69$ & $L L=1.131 \quad U L=4.388$ & $Z=3.321$ & $P=0.001$ \\
\hline & & $S M D_{\text {Overall }}=1.575$ & $S E=0.446$ & $V=0.199$ & $L L=0.701 \quad U L=2.449$ & $Z=3.531$ & $P<0.001$ \\
\hline & Published & $S M D_{A}=1.869$ & $S E=0.54$ & $V=0.292$ & $L L=0.811 \quad U L=2.927$ & $Z=3.461$ & $P=0.001$ \\
\hline & & $S M D_{B}=1.141$ & $S E=0.634$ & $V=0.402$ & $L L=-0.101 \quad U L=2.383$ & $Z=1.8$ & $P=0.072$ \\
\hline & & $S M D_{\text {Overall }}=1.563$ & $S E=0.411$ & $V=0.169$ & $L L=0.757 \quad U L=2.368$ & $Z=3.802$ & $P<0.001$ \\
\hline Hospital & Sample & $S M D_{A}=0.034$ & $S E=0.518$ & $V=0.268$ & $L L=-0.981 \quad U L=1.05$ & $Z=0.066$ & $P=0.947$ \\
\hline & & $S M D_{B}=1.603$ & $S E=0.316$ & $V=0.1$ & $L L=0.984 \quad U L=2.221$ & $Z=5.08$ & $P<0.001$ \\
\hline & & $S M D_{\text {Overall }}=1.179$ & $S E=0.269$ & $V=0.073$ & $L L=0.65 \quad U L=1.707$ & $Z=4.373$ & $P<0.001$ \\
\hline & Continent & $S M D_{A m}=0.05$ & $S E=0.512$ & $V=0.262$ & $L L=-0.954 U L=1.054$ & $Z=0.098$ & $P=0.922$ \\
\hline & & $S M D_{A S}=1.494$ & $S E=0.413$ & $V=0.171$ & $L L=0.684 \quad U L=2.303$ & $Z=3.616$ & $P<0.001$ \\
\hline & & $S M D_{\mathrm{EU}}=1.674$ & $S E=0.455$ & $V=0.207$ & $L L=0.782 \quad U L=2.565$ & $Z=3.68$ & $P<0.001$ \\
\hline & & $S M D_{\text {Overall }}=1.174$ & $S E=0.263$ & $V=0.069$ & $L L=0.66 \quad U L=1.689$ & $Z=4.473$ & $P<0.001$ \\
\hline & Published & $S M D_{A}=1.573$ & $S E=0.432$ & $V=0.187$ & $L L=0.726 \quad U L=2.42$ & $Z=3.64$ & $P<0.001$ \\
\hline & & $S M D_{B}=0.822$ & $S E=0.43$ & $V=0.185$ & $L L=-0.021 \quad U L=1.665$ & $Z=1.91$ & $P=0.056$ \\
\hline & & $S M D_{\text {Overall }}=1.196$ & $S E=0.305$ & $V=0.093$ & $L L=0.598 \quad U L=1.793$ & $Z=3.922$ & $P<0.001$ \\
\hline
\end{tabular}

$O R$ - odds ratio, SMD - standard mean difference, $V$-variance, $S E$ - standard error, $L L$ - lower limit, UL - upper limit. 
Table VIII. Heterogeneity subgroup analysis of mortality, recurrence, failure, operating time, postoperative hospital stay based on sample size, continent, and published year in 13 studies

\begin{tabular}{|c|c|c|c|c|c|}
\hline \multirow[t]{16}{*}{ Mortality } & \multirow[t]{5}{*}{ Sample size } & $Q \mathrm{a}=0.061$ & $\mathrm{D} f=1$ & $P=0.804$ & $1^{2}=0$ \\
\hline & & $Q b=7.766$ & $\mathrm{D} f=3$ & $P=0.051$ & $P^{2}=61.372$ \\
\hline & & Qwithin $=7.828$ & $\mathrm{D} f=4$ & $P=0.098$ & \\
\hline & & Qbetween $=0.799$ & $\mathrm{D} f=1$ & $P=0.372$ & \\
\hline & & Qoverall = 8.626 & $\mathrm{D} f=5$ & $P=0.125$ & $I^{2}=42.038$ \\
\hline & \multirow[t]{6}{*}{ Continent } & Qam $=0.396$ & $\mathrm{D} f=1$ & $P=0.529$ & $I^{2}=0$ \\
\hline & & Qas $=1.156$ & $\mathrm{D} f=1$ & $P=0.282$ & $I^{2}=13.462$ \\
\hline & & $Q \mathrm{Eu}=0.883$ & $\mathrm{D} f=1$ & $P=0.347$ & $1^{2}=0$ \\
\hline & & Qwithin $=2.435$ & $\mathrm{D} f=3$ & $P=0.487$ & \\
\hline & & Qbetween $=6.191$ & $\mathrm{D} f=2$ & $P=0.045$ & \\
\hline & & Qoverall = 8.626 & $\mathrm{D} f=5$ & $P=0.125$ & $I^{2}=42.038$ \\
\hline & \multirow[t]{5}{*}{ Published year } & $Q a=4.257$ & $\mathrm{D} f=2$ & $P=0.119$ & $P^{2}=53.014$ \\
\hline & & $Q b=0.427$ & $\mathrm{D} f=2$ & $P=0.808$ & $I^{2}=0$ \\
\hline & & Qwithin $=4.683$ & $\mathrm{D} f=4$ & $P=0.321$ & \\
\hline & & Qbetween $=3.415$ & $\mathrm{D} f=1$ & $P=0.065$ & \\
\hline & & Qoverall = 8.626 & $\mathrm{D} f=5$ & $P=0.125$ & $I^{2}=42.038$ \\
\hline \multirow[t]{15}{*}{ Recurrence } & \multirow[t]{5}{*}{ Sample size } & $Q \mathrm{a}=1.343$ & $\mathrm{D} f=2$ & $P=0.511$ & $P^{2}=0$ \\
\hline & & $Q b=0.00$ & $\mathrm{D} f=0$ & $P=1$ & $1^{2}=0$ \\
\hline & & Qwithin $=1.343$ & $\mathrm{D} f=2$ & $P=0.511$ & \\
\hline & & Qbetween $=9.533$ & $\mathrm{D} f=1$ & $P=0.002$ & \\
\hline & & Qoverall = 10.877 & $\mathrm{D} f=3$ & $P=0.012$ & $I^{2}=72.418$ \\
\hline & \multirow[t]{5}{*}{ Continent } & $Q a m=10.653$ & $\mathrm{D} f=1$ & $P=0.001$ & $R^{2}=90.613$ \\
\hline & & $Q E u=0.037$ & $\mathrm{D} f=1$ & $P=0.847$ & $I^{2}=0$ \\
\hline & & Qwithin $=10.69$ & $\mathrm{D} f=2$ & $P=0.005$ & \\
\hline & & Qbetween $=0.187$ & $\mathrm{D} f=1$ & $P=0.666$ & \\
\hline & & Qoverall = 10.877 & $\mathrm{D} f=3$ & $P=0.012$ & $I^{2}=72.418$ \\
\hline & \multirow[t]{5}{*}{ Published year } & $Q \mathrm{a}=0.037$ & $\mathrm{D} f=1$ & $P=0.847$ & $1^{2}=0$ \\
\hline & & $Q b=10.653$ & $\mathrm{D} f=1$ & $P=0.001$ & $1^{2}=90.613$ \\
\hline & & Qwithin $=10.69$ & $\mathrm{D} f=2$ & $P=0.005$ & \\
\hline & & Qbetween $=0.187$ & $\mathrm{D} f=1$ & $P=0.666$ & \\
\hline & & Qoverall = 10.877 & $\mathrm{D} f=3$ & $P=0.012$ & $I^{2}=72.418$ \\
\hline \multirow[t]{16}{*}{ Failure } & \multirow[t]{5}{*}{ Sample size } & $Q \mathrm{a}=12.832$ & $\mathrm{D} f=2$ & $P=0.002$ & $I^{2}=84.413$ \\
\hline & & $Q b=18.288$ & $\mathrm{D} f=7$ & $P=0.011$ & $P^{2}=61.724$ \\
\hline & & Qwithin = 31.12 & $\mathrm{D} f=9$ & $P<0.001$ & \\
\hline & & Qbetween $=0.248$ & $\mathrm{D} f=1$ & $P=0.619$ & \\
\hline & & Qoverall = 31.763 & $\mathrm{D} f=10$ & $P<0.001$ & $R^{2}=68.517$ \\
\hline & \multirow[t]{6}{*}{ Continent } & Qam $=0.986$ & $\mathrm{D} f=2$ & $P=0.611$ & $1^{2}=0$ \\
\hline & & Qas $=1$ & $\mathrm{D} f=3$ & $P=0.801$ & $I^{2}=0$ \\
\hline & & $Q \mathrm{Eu}=21.359$ & $\mathrm{D} f=3$ & $P<0.001$ & $R^{2}=85.954$ \\
\hline & & Qwithin $=23.344$ & $\mathrm{D} f=8$ & $P=0.003$ & \\
\hline & & Qbetween $=4.647$ & $\mathrm{D} f=2$ & $P=0.098$ & \\
\hline & & Qoverall = 31.763 & $\mathrm{D} f=10$ & $P<0.001$ & $I^{2}=68.517$ \\
\hline & \multirow[t]{5}{*}{ Published year } & $Q \mathrm{a}=18.084$ & $\mathrm{D} f=4$ & $P=0.001$ & $R^{2}=77.881$ \\
\hline & & $Q b=9.968$ & $\mathrm{D} f=5$ & $P=0.076$ & $R^{2}=49.838$ \\
\hline & & Qwithin $=28.052$ & $\mathrm{D} f=9$ & $P=0.001$ & \\
\hline & & Qbetween $=1.697$ & $\mathrm{D} f=1$ & $P=0.193$ & \\
\hline & & Qoverall = 31.763 & $\mathrm{D} f=10$ & $P<0.001$ & $P^{2}=68.517$ \\
\hline
\end{tabular}


Table VIII. Cont.

\begin{tabular}{|c|c|c|c|c|c|}
\hline \multirow{16}{*}{$\begin{array}{l}\text { Operating } \\
\text { time }\end{array}$} & \multirow[t]{5}{*}{ Sample size } & $Q a=57.001$ & $\mathrm{D} f=2$ & $P<0.001$ & $1^{2}=96.491$ \\
\hline & & $Q b=40.424$ & $\mathrm{D} f=3$ & $P<0.001$ & $I^{2}=92.579$ \\
\hline & & Qwithin $=97.425$ & $\mathrm{D} f=5$ & $P<0.001$ & \\
\hline & & Qbetween = 3.207 & $\mathrm{D} f=1$ & $P=0.073$ & \\
\hline & & Qoverall $=122.944$ & $\mathrm{D} f=6$ & $P<0.001$ & $P^{2}=95.12$ \\
\hline & \multirow[t]{6}{*}{ Continent } & $Q_{\mathrm{am}}=5.526$ & $\mathrm{D} f=1$ & $P=0.019$ & $P^{2}=81.903$ \\
\hline & & $Q_{\mathrm{as}}=5.836$ & $\mathrm{D} f=2$ & $P=0.054$ & $R^{2}=65.727$ \\
\hline & & $Q_{\mathrm{eu}}=38.301$ & $\mathrm{D} f=1$ & $P<001$ & $P^{2}=97.389$ \\
\hline & & Qwithin $=49.662$ & $\mathrm{D} f=4$ & $P<0.001$ & \\
\hline & & $Q_{\text {between }}=73.282$ & $\mathrm{D} f=2$ & $P<0.001$ & \\
\hline & & $Q_{\text {overal }}=122.944$ & $\mathrm{D} f=6$ & $P<0.001$ & $P^{2}=95.12$ \\
\hline & \multirow[t]{5}{*}{ Published year } & $Q a=43.127$ & $\mathrm{D} f=3$ & $P<0.001$ & $1^{2}=93.044$ \\
\hline & & $Q b=29.038$ & $\mathrm{D} f=2$ & $P<0.001$ & $R^{2}=93.113$ \\
\hline & & Qwithin $=72.165$ & $\mathrm{D} f=5$ & $P<0.001$ & \\
\hline & & Qbetween $=0.765$ & $\mathrm{D} f=1$ & $P=0.382$ & \\
\hline & & Qoverall $=122.944$ & $\mathrm{D} f=6$ & $P<0.001$ & $R^{2}=95.12$ \\
\hline \multirow{16}{*}{$\begin{array}{l}\text { Hospital } \\
\text { stay }\end{array}$} & \multirow[t]{5}{*}{ Sample size } & $Q a=28.081$ & $\mathrm{D} f=2$ & $P<0.001$ & $1^{2}=92.878$ \\
\hline & & $Q b=163.122$ & $\mathrm{D} f=8$ & $P<0.001$ & $I^{2}=95.096$ \\
\hline & & Qwithin = 191.203 & $\mathrm{D} f=10$ & $P<0.001$ & \\
\hline & & Qbetween $=6.683$ & $\mathrm{D} f=1$ & $P=0.01$ & \\
\hline & & Qoverall $=273.366$ & $\mathrm{D} f=11$ & $P<0.001$ & $R^{2}=95.976$ \\
\hline & \multirow[t]{6}{*}{ Continent } & Qam $=23.83$ & $\mathrm{D} f=2$ & $P<0.001$ & $R^{2}=91.607$ \\
\hline & & Qas $=45.187$ & $\mathrm{D} f=4$ & $P<0.001$ & $I^{2}=91.148$ \\
\hline & & $Q \mathrm{Eu}=86.565$ & $\mathrm{D} f=3$ & $P<0.001$ & $R^{2}=96.534$ \\
\hline & & Qwithin $=155.581$ & $\mathrm{D} f=9$ & $P<0.001$ & \\
\hline & & Qbetween = 6.619 & $\mathrm{D} f=2$ & $P=0.037$ & \\
\hline & & Qoverall $=273.366$ & $\mathrm{D} f=11$ & $P<0.001$ & $1^{2}=95.976$ \\
\hline & \multirow[t]{5}{*}{ Published year } & $Q \mathrm{a}=145.571$ & $\mathrm{D} f=5$ & $P<0.001$ & $R^{2}=96.565$ \\
\hline & & $Q b=105.571$ & $\mathrm{D} f=5$ & $P<0.001$ & $1^{2}=95.264$ \\
\hline & & Qwithin = 251.142 & $\mathrm{D} f=10$ & $P<0.001$ & \\
\hline & & Qbetween $=1.517$ & $\mathrm{D} f=1$ & $P=0.218$ & \\
\hline & & Qoverall $=273.366$ & $\mathrm{D} f=11$ & $P<0.001$ & $I^{2}=95.976$ \\
\hline
\end{tabular}

all show no, more, and more differences considering their SMD for a hospital stay in open thoracotomy decortication versus VATS (Figure $4 \mathrm{C})$. Heterogeneity subgroup analyses in subgroups $A$ and $B$ show a considerable amount of heterogeneity. Subgroup analysis of sample size $\left(Q_{\text {between }}=6.683, \mathrm{~d} f=1\right.$, and $\left.p=0.01\right)$ can explain $R^{2}=14.28 \%$ of variance within studies. Furthermore, the subgroup analyses of the continent show no, more, more, and more differences considering their SMD of hospital stay in open thoracotomy decortication compared to VATS (Figure 4 I). Moreover, heterogeneity subgroup analyses in America, Asia, and Europe show considerable heterogeneity for each. However, the subgroup analyses of the continent $\left(Q_{\text {between }}=6.619\right.$, $\mathrm{d} f=2$ and $p=0.037$ ) can explain $R^{2}=19.12 \%$ of variance within studies. The subgroup analyses of the published year in subgroup A, subgroup B, and overall show more, no and more difference considering their SMD of hospital stay in open thoracotomy decortication compared to those of VATS (Figure $4 \mathrm{G}$ ). Heterogeneity subgroup analyses in subgroups $A$ and $B$ show a considerable amount of heterogeneity. Finally, subgroup analysis of published year $\left(Q_{\text {between }}=1.517, \mathrm{~d} f=1, p=\right.$ 0.218 ) cannot explain the variance within studies (listed in Tables VII and VIII).

\section{Publication bias}

The funnel plots of seven outcomes are illustrated (Figure 5). These outcomes used for identifying the publication bias are based on Egger's regression test, which reveals no evidence for publication bias in two treatment procedures con- 
A

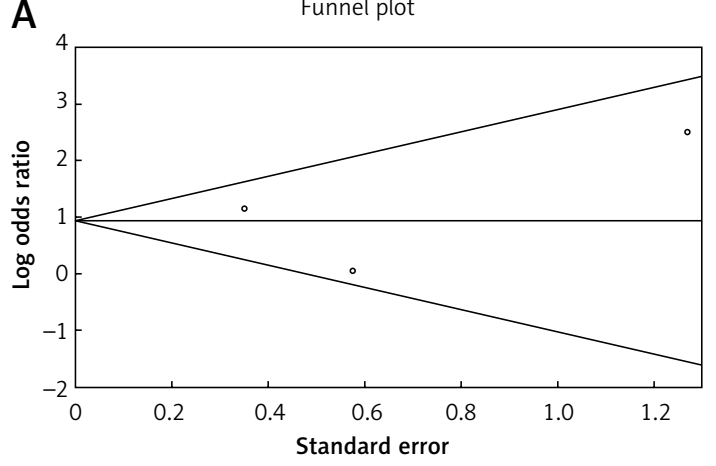

C

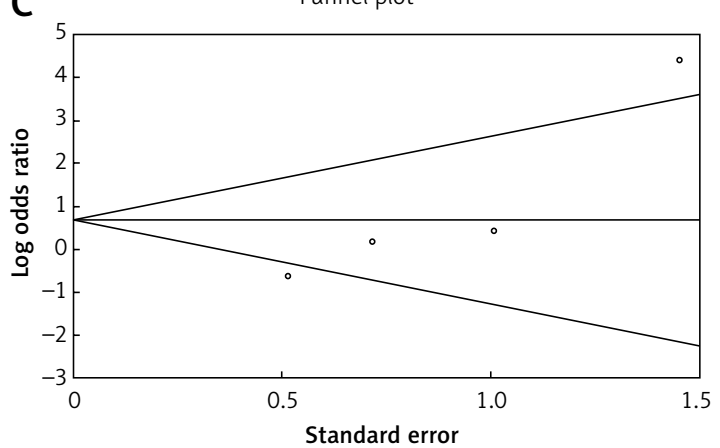

$E_{4.5}$

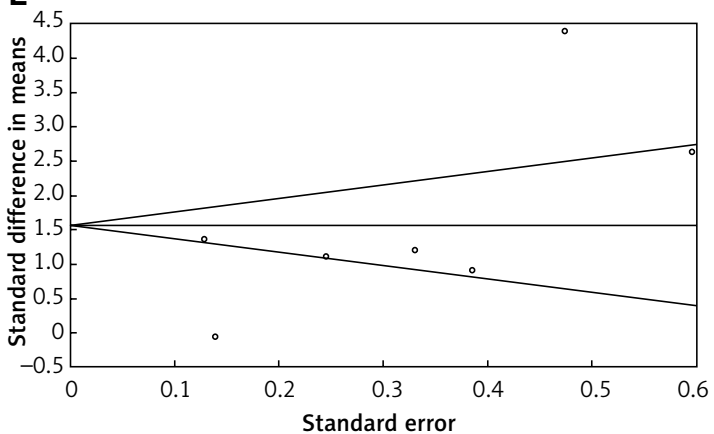

G

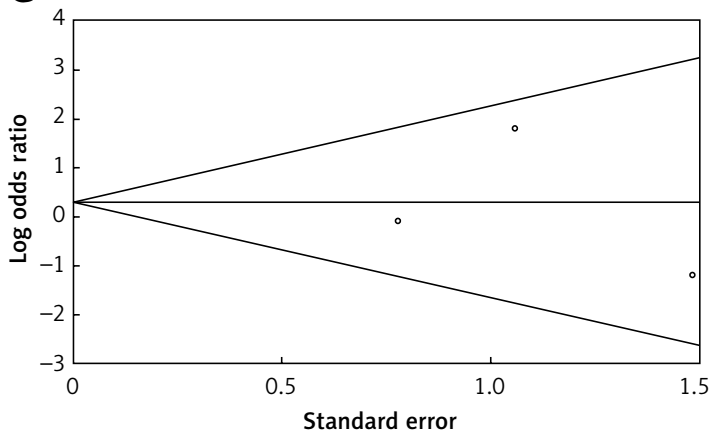

B
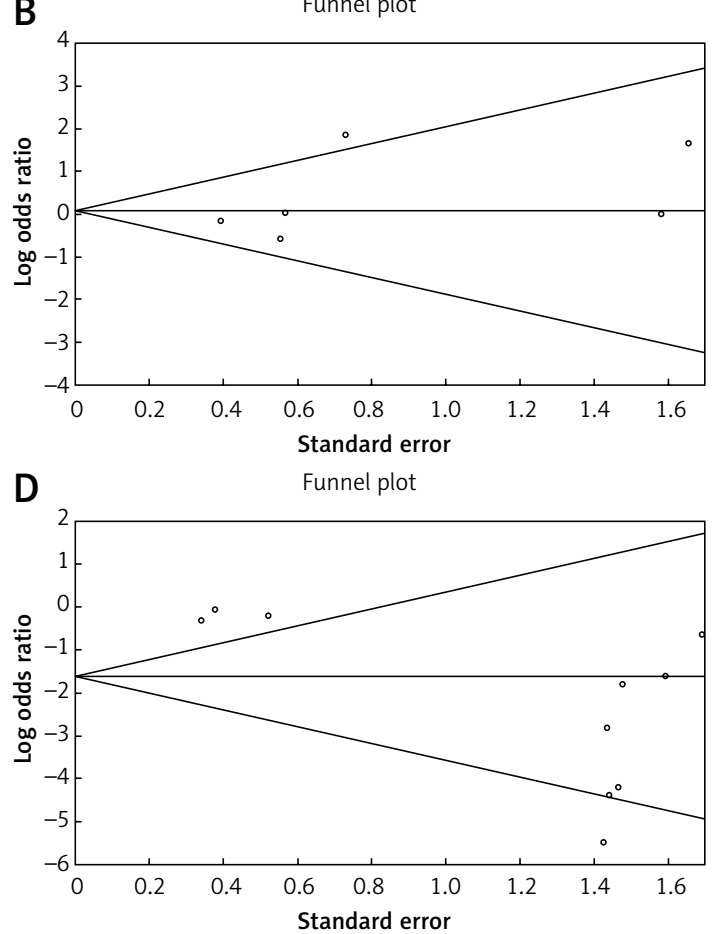

$\mathrm{F}$

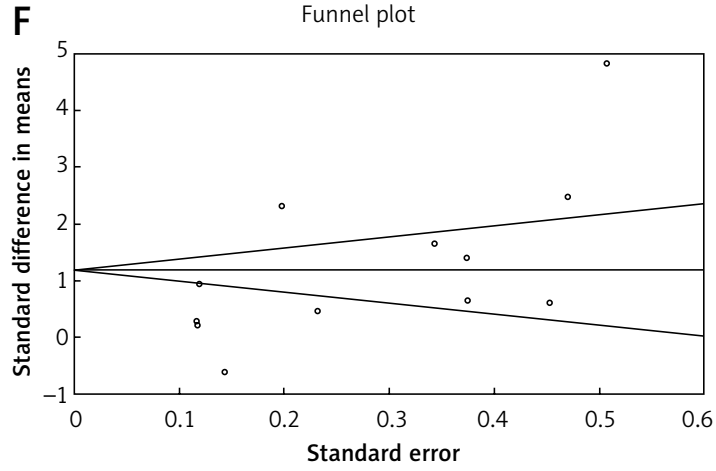

Figure 5. Funnel plots between two procedures for postoperative prolonged air leakage (A), mortality (B), recurrence $(C)$, failure or converted operations (D), time of operation (E), hospital stay (F), and wound infection (G)

sidering the outcomes except for the outcome of failure and converted operations (Table IX).

According to the identified publication bias, five imputable studies were found using the trim and fill method on the right side of the funnel plot (Figure 6) (odds ratio $=0.66637$, lower limit $=0.24066$, upper limit $=1.84512, Q=67.84948, p=0.4347$ ). This result shows that despite adding these studies, there are no differences in the outcome of

failure and conversion operations using VATS and open thoracotomy decortication. It has to be noted that 5 imputable studies in which open thoracotomy decortication was a failure were missed or not officially published or were selectively reported.

\section{Discussion}

The current systematic review and meta-analysis showed no promising trends toward the advantages 
Table IX. Egger's regression test for identifying the publication bias for seven outcomes

\begin{tabular}{|lccccccc|}
\hline Outcome & Intercept & $P$-value & SE & Lower limit & Upper limit & $t$-value & $\mathrm{d} f$ \\
\hline $\begin{array}{l}\text { Prolonged air } \\
\text { leakage }\end{array}$ & 0.513 & 0.884 & 2.790 & -34.935 & 35.96 & 0.184 & 1 \\
\hline Mortality & 1.309 & 0.354 & 1.249 & -2.158 & 4.776 & 1.048 & 4 \\
\hline Recurrence & 4.361 & 0.073 & 1.250 & -1.017 & 9.740 & 3.489 & 2 \\
\hline $\begin{array}{l}\text { Failure or converted } \\
\text { operations }\end{array}$ & -2.293 & 0.0034 & 0.583 & -3.612 & -0.975 & 3.934 & 9 \\
\hline Times of operations & 4.644 & 0.211 & 3.235 & -3.671 & 12.959 & 1.436 & 5 \\
\hline Hospital stays & 5.3994 & 0.0668 & 2.6262 & -0.4502 & 11.2509 & 2.056 & 10 \\
\hline Wound infection & 0.5309 & 0.9190 & 4.1504 & -53.2668 & 52.2490 & 0.1279 & 1 \\
\hline
\end{tabular}

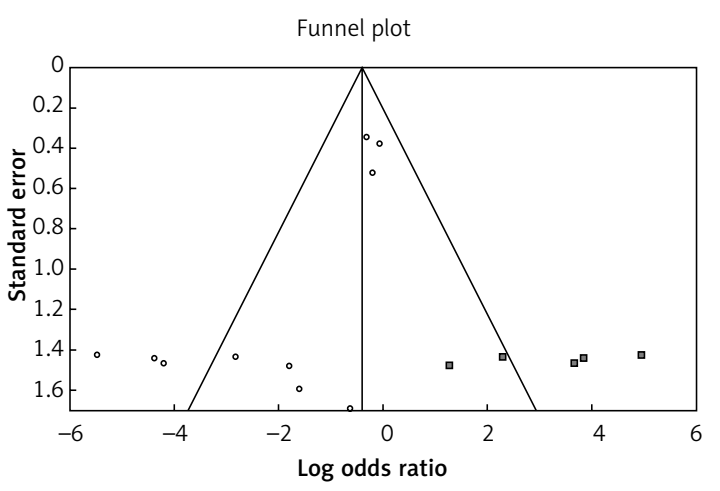

Figure 6. Trim and fill analysis for determining missing studies for failure or converted operations outcome

of VATS in empyema thoracis. The results illustrated that the outcomes (i.e., hospital stay, and times of operations) of VATS are worse than those of open thoracotomy decortication. Generally, it is related to the time of performing anatomical opening and closing of the thoracotomy, which takes about 30-45 min. However, this period of time for opening and closing is omitted in the VATS procedure. It has also been shown that the rates of postoperative prolonged air leakage, wound infection, mortality and recurrence of either procedure had no advantage over the other. Moreover, although failures or converted operations in VATS were more frequent, due to the missing or selectively reported studies revealed by the trim and fill technique, it can be deduced that at least one of the procedures had no superiority over the other. The findings of this study indicated that VATS and open surgery decortication have an important place in empyema thoracis treatment and neither of them has advantages over the other.

Since Hippocrates' day, open drainage of empyema has remained the only means of managing the late stages of empyema. Since that time, open thoracotomy decortication has been well accepted for definitive treatment of stages II and III of empyema [2].

Today, VATS is used as a very effective technique for treating stages II and III of empyema
[1]. So, it is necessary to analyze the outcomes of VATS and open thoracotomy decortication using a systematic review and meta-analysis approach.

Today, there are several challenges to effectively treat empyema thoracis with both traditional and new approaches $[23,24,28,35,36]$. Some authors are in favor of performing VATS for treating empyema thoracis compared to open thoracotomy decortication [37].

Our literature review showed that there were only one systematic review and meta-analysis and no randomized controlled trial studies (RCTs) for comparing the VATS and open thoracotomy decortication [38]. Pan et al.'s study was performed on five studies, and they compared outcomes of VATS and open thoracotomy decortication. The results of hospital stay and operating time of VATS decortication are similar to ours with a lower mortality rate. Additionally, the postoperative prolonged air leakage of VATS decortication is less in Pan et al.'s study, while in the current study it has no advantages for both procedures. Recurrence outcome in the current study is less in both procedures, while Pan et al. reported only that of VATS decortication. Pan et al. did not report about the failure or conversion rate of VATS, while that rate in the current study for VATS is more than that of open thoracotomy decortication. Also, wound infection results of both procedures have no superiority over each other, while in the Pan et al. study, no information about this outcome was reported. Finally, they concluded that VATS decortication can be considered safe for selecting the first procedure in the management of empyema. Because of the small number of included studies in the Pan et al. meta-analysis, they found no heterogeneity in their study and hence meta-regression was not performed [39].

The current results should be considered along with the limitations of the included studies. Since designing and performing prospective RCT studies for the treatment of empyema according to ethical considerations is a difficult task, no RCTs were found to be included in this study. 
The included studies were derived from PubMed, Scopus, and Google Scholar databases. Therefore, unpublished articles were not included since any systematic review might have unavoidable publication bias. In this study, publication bias was analyzed using graphical funnel plots and Egger's regression test, where only one outcome with possible publication bias was seen. However, the trim and fill algorithm estimated that at least five potential studies have been missed.

Because of the retrospective nature of the study, surgeons with various individual surgical and treatment skills participated in included studies, which can influence the overall results. Surgeons' bias is one of the limitations due to which many impactful studies may need to be excluded due to the absence of in-depth details for each patient such as treatment failure features [40].

So, a standard protocol for assessing the professionalism in surgeons is needed [41, 42]. Treatment selection bias is hard to assess and can be mostly eliminated in RCTs [43], and in the absence of RCTs, the propensity score matching is calculated [44]. However, it has been stated that "To date, there is no clear indication of whether propensity scores can remove the selection bias that jeopardizes quasi-experiments" [45]. Hence avoiding the surgeon bias has remained as a limitation; however, a portion of this can be determined through publication bias, which is mostly about selective reports.

For this purpose, it is suggested to report the outcomes by including the surgeons' properties with respect to skills, years of surgery experience as well as educational background and facilities. Then, the surgeon bias can be evaluated using meta-regression and subgroup analyses. Additionally, the guideline of chest imaging for performing either of two procedures includes persistent pleural collections despite attempted drainage, restricted lung expansion, lung trapped by the pleural peel (it is described as "an inelastic membrane composed of fibroblasts that develops during the organization stage of a parapneumonic effusion and encases the lung, thus limiting its functional capability and resulting in trapped lung". [46]), and multiloculation. However, there was no information on chest imaging, and hence the analysis for the selection of surgical approaches based on imaging was not feasible. Most of the time, the selection of surgical procedures depends on the estimated stages of empyema based on surgeons' selection, which could be named surgeon's bias as mentioned above. Insufficient data reported for the remaining postoperative complications (i.e., there were less than three studies that included those outcome measurements) is another limitation of this study which excludes them from further analysis.

Finally, to achieve reasonable results in these types of studies, performing more RCT studies with a sufficient sample size according to ethical issues is recommended for future systematic reviews and meta-analysis studies.

The current meta-analysis results confirmed that VATS is the best approach for reducing duration of hospital stay and time of operation with equivalent results for recurrence, postoperative prolonged air leakage, wound infection, and mortality in treating empyema thoracis.

Indeed, this meta-analysis may show that most often the VATS procedure was used at uncomplicated or stage I and stage II, or rarely at stage III of empyema; however, the results on the stages were cumulatively reported in the studies. On the other hand, open thoracotomy decortication was able to treat all stages consisting of complicated/uncomplicated forms of empyema thoracis and failure of VATS. Eventually, converted VATS decortication and its postoperative complications were finally treated by open surgery. Taking into account the results for the seven abovementioned outcomes, this study did not decrease the importance of open surgery.

Moreover, the results of the current study confirmed the American Association of Thoracic Surgery Guidelines (AATSG) for management of empyema in which VATS is presented as the first line approach in all patients with stage II acute empyema [47], and the European Association of Cardiothoracic Surgery expert consensus statement for surgical management of pleural empyema demonstrated benefits for surgical decortication by VATS at stages II and III of empyema, which are acceptable to undergo an operative procedure [48]. The only difference of this study is the presence of some limitations in performing the VATS procedure at stage III of empyema.

In conclusion, worldwide, the beneficial effects of VATS have been widely reported in treatment of early stages of empyema (i.e., stage II, with limited successful performance at stage III). The results of the current systematic review and meta-analysis suggest no major trends of superior outcomes with VATS versus open surgery decortication in the treatment of empyema thoracis. Hence, VATS and open thoracotomy decortication could be recommended in the treatment of empyema thoracis. However, failed or converted patients from VATS as well as those in advanced stages of empyema can be well managed by open thoracotomy decortication.

\section{Availability}

The stand alone meta-mums tool is available on request through the corresponding authors.

\section{Acknowledgments}

This study is part of a PhD thesis (No. 931507) and was approved and supported by Research 
Council of Mashhad University of Medical Sciences, Mashhad, Iran and carried out in Nuclear Medicine Research Center of Mashhad University of Medical Sciences, Mashhad, Iran.

\section{Conflict of interest}

The authors declare no conflict of interest.

\section{References}

1. Hajjar WM, Ahmed I, Al-Nassar SA, et al. Video-assisted thoracoscopic decortication for the management of late stage pleural empyema, is it feasible? Ann Thorac Med 2016; 11: 71-8.

2. Perry Y, Linden PA. Empyema. In: Sabiston and Spencer Surgery of the Chest. Sellke FW, Del Nido PJ, Swanson SJ (eds.). Saunders/Elsevier, Philadelphia 2016; 467-74.

3. Light RW. Parapneumonic effusions and empyema. Proc Am Thorac Soc 2006; 3: 75-80.

4. Luh SP, Chou MC, Wang LS, et al. Video-assisted thoracoscopic surgery in the treatment of complicated parapneumonic effusions or empyemas: outcome of $234 \mathrm{pa}-$ tients. Chest 2005; 127: 1427-32.

5. Colice GL, Curtis A, Deslauriers J, et al. Medical and surgical treatment of parapneumonic effusions: an evidence-based guideline. Chest 2000; 118: 1158-71.

6. Mc Laughlin JS, Krasna MJ. Parapneumpnic empyema. In: General Thoracic Durgery (Shields). Shields TW, LoCicero III J, Ponn RB, et al. (eds.). Lippincot Williams \& Wilkins, Philadelphia 2005; 819-32.

7. Mazidi M, Rezaie P, Banach M. Effect of magnesium supplements on serum C-reactive protein: a systematic review and meta-analysis. Arch Med Sci 2018; 14: 707-16.

8. Baoning Q, Chuandao S, Na S, et al. Efficacy and safety of radio-chemotherapy combined with thermotherapy for advanced cervical cancer in Chinese women: a meta-analysis. Arch Med Sci Civil Dis 2017; 2: 182-90.

9. Liu Y, Meng F, Yang G, et al. Comparison of intra-articular versus intravenous application of tranexamic acid in total knee arthroplasty: a meta-analysis of randomized controlled trials. Arch Med Sci 2017; 13: 533-40.

10. Huang R, Zhong T, Wu H. Quercetin protects against lipopolysaccharide-induced acute lung injury in rats through suppression of inflammation and oxidative stress. Arch Med Sci 2015; 11: 427-32.

11. Moher D, Liberati A, Tetzlaff J, et al. Preferred reporting items for systematic reviews and meta-analyses: the PRISMA statement. Ann Intern Med 2009; 151: 264-9, w64.

12. Moher D, Liberati A, Tetzlaff J, et al. Preferred reporting items for systematic reviews and meta-analyses: the PRISMA statement. Int J Surg 2010; 8: 336-41.

13. Borenstein M, Hedges L, Higgins J, et al. Comprehensive Meta-Analysis Version 2. Engelwood, NJ, Biostat 2009.

14. Higgins JPT, Green S. Cochrane Handbook for Systematic Reviews of Interventions Version 5.1.0 [updated March 2011]: The Cochrane Collaboration; 2011.

15. Egger M, Davey Smith G, Schneider M, et al. Bias in meta-analysis detected by a simple, graphical test. BMJ 1997; 315: 629-34.

16. Sterne JA, Egger M. Funnel plots for detecting bias in meta-analysis: guidelines on choice of axis. J Clin Epidemiol 2001; 54: 1046-55.

17. Jin ZC, Wu C, Zhou XH, et al. A modified regression method to test publication bias in meta-analyses with binary outcomes. BMC Med Res Methodol 2014; 14: 132.
18. Rucker G, Schwarzer G, Carpenter J. Arcsine test for publication bias in meta-analyses with binary outcomes. Stat Med 2008; 27: 746-63.

19. Peters JL, Sutton AJ, Jones DR, et al. Performance of the trim and fill method in the presence of publication bias and between-study heterogeneity. Stat Med 2007; 26: 4544-62.

20. Duval S, Tweedie R. Trim and fill: a simple funnel-plotbased method of testing and adjusting for publication bias in meta-analysis. Biometrics 2000; 56: 455-63.

21. Chung JH, Lee SH, Kim KT, et al. Optimal timing of thoracoscopic drainage and decortication for empyema. Ann Thorac Surg 2014; 97: 224-9.

22. Marks DJB, Fisk MD, Koo CY, et al. Thoracic empyema: a 12-year study from a UK tertiary cardiothoracic referral centre. PLoS One 2012; 7: e30074.

23. Cardillo G, Carleo F, Carbone L, et al. Chronic postpneumonic pleural empyema: comparative merits of thoracoscopic versus open decortication. Eur J Cardiothorac Surg 2009; 36: 914-8.

24. Chan DT, Sihoe AD, Chan S, et al. Surgical treatment for empyema thoracis: is video-assisted thoracic surgery "better" than thoracotomy? Ann Thorac Surg 2007; 84: 225-31.

25. Lardinois D, Gock M, Pezzetta E, et al. Delayed referral and Gram-negative organisms increase the conversion thoracotomy rate in patients undergoing video-assisted thoracoscopic surgery for empyema. Ann Thorac Surg 2005; 79: 1851-6.

26. Waller DA, Rengarajan A, Nicholson FH, et al. Delayed referral reduces the success of video-assisted thoracoscopic debridement for post-pneumonic empyema. Respir Med 2001; 95: 836-40.

27. Podbielski FJ, Maniar HS, Rodriguez HE, et al. Surgical strategy of complex empyema thoracis. JSLS 2000; 4: 287-90.

28. Lawrence DR, Ohri SK, Moxon RE, et al. Thoracoscopic debridement of empyema thoracis. Ann Thorac Surg 1997; 64: 1448-50.

29. Terra RM, Waisberg DR, Almeida JL, et al. Does videothoracoscopy improve clinical outcomes when implemented as part of a pleural empyema treatment algorithm? Clinics 2012; 67: 557-64.

30. Tong BC, Hanna J, Toloza EM, et al. Outcomes of videoassisted thoracoscopic decortication. Ann Thorac Surg 2010; 89: 220-5.

31. Bačić I, Morović D, Sulen N, et al. Surgery treatment of pleural empyema with minimally invasive method at the Thoracic Surgery Department in Zadar General Hospital. Medica Jadertina 2015; 45: 25-7.

32. Brotis AG, Tasiou A, Giannis T, et al. Collagen type-I A2 gene polymorphisms and susceptibility to intracranial aneurysms: a meta-analysis of genetic association studies. Int J Neurosci 2018; 128: 640-53.

33. Dahabreh IJ, Linardou H, Kosmidis $\mathrm{P}$, et al. EGFR gene copy number as a predictive biomarker for patients receiving tyrosine kinase inhibitor treatment: a systematic review and meta-analysis in non-small-cell lung cancer. Ann Oncol 2011; 22: 545-52.

34. Palma S, Delgado-Rodriguez M. Assessment of publication bias in meta-analyses of cardiovascular diseases. J Epidemiol Commun Health 2005; 59: 864-9.

35. Melloni G, Carretta A, Ciriaco P, et al. Decortication for chronic parapneumonic empyema: results of a prospective study. World J Surg 2004; 28: 488-93.

36. Zahid I, Nagendran M, Routledge T, et al. Comparison of video-assisted thoracoscopic surgery and open surgery in the management of primary empyema. Curr Opin Pulmonary Med 2011; 17: 255-9. 
37. Chambers A, Routledge T, Dunning J, et al. Is video-assisted thoracoscopic surgical decortication superior to open surgery in the management of adults with primary empyema? Interact Cardiovasc Thorac Surg 2010; 11: 171-7.

38. Redden MD, Chin TY, van Driel ML. Surgical versus nonsurgical management for pleural empyema. Cochrane Database Syst Rev 2017; 3: CD010651.

39. Pan H, He J, Shen J, et al. A meta-analysis of video-assisted thoracoscopic decortication versus open thoracotomy decortication for patients with empyema. J Thorac Dis 2017; 9: 2006-14.

40. Dewan MC, Lim J, Shannon CN, et al. The durability of endoscopic third ventriculostomy and ventriculoperitoneal shunts in children with hydrocephalus following posterior fossa tumor resection: a systematic review and time-to-failure analysis. J Neurosurg Pediatr 2017; 19: 578-84.

41. Dreyer JS. Assessing professionalism in surgeons. Surgeon 2010; 8: 20-7.

42. Glogowska O, Glogowski M, Szmit S. Intensive rehabilitation as an independent determinant of better outcome in patients with lung tumors treated by thoracic surgery. Arch Med Sci 2017; 13: 1442-8.

43. Kwaan MR, Melton GB. Evidence-based medicine in surgical education. Clin Colon Rectal Surg 2012; 25: 151-5.

44. Littnerova S, Jarkovsky J, Parenica J, et al. Why to use propensity score in observational studies? Case study based on data from the Czech clinical database AHEAD 2006-09. Cor et Vasa 2013; 55: e383-90.

45. Olmos A, Govindasamy P. Propensity scores: a practical introduction using R. J MultiDiscipl Eval 2015; 11: 68-87.

46. Pleural Peel. In: Encyclopedia of Intensive Care Medicine. Vincent JL, Hall JB (eds.). Springer Berlin Heidelberg 2012; 1756

47. $95^{\text {th }}$ Annual Meeting of American Association for Thoracic Surgery Washington State Convention Center, Seattle, WA, USA 2015.

48. Scarci M, Abah U, Solli P, et al. EACTS expert consensus statement for surgical management of pleural empyema. Eur J Cardiothorac Surg 2015; 48: 642-53. 